\title{
MYRRH - COMMIPHORA CHEMISTRY
}

\author{
Lumír O. Hanuša*, Tomáš Řezanka ${ }^{\mathrm{b}}$, Valery M. Dembitskya, \\ Arieh Moussaieffa
}

\author{
a Department of Medicinal Chemistry and Natural Products, School of Pharmacy, Hebrew University, Ein Kerem Campus, \\ Jerusalem 91120, Israel \\ b Institute of Microbiology, Czech Academy of Sciences, Videňská 1083, Prague, 14220 \\ Czech Republic \\ e-mail:lumir@cc.huji.ac.il
}

Received: May 25, 2005; Accepted: June 5, 2005

Key words: Myrrh/Commiphora

Myrrh and opopanax has been used throughout history in incense and as a perfume. Since Bible times it has been used for the treatment of wounds. The first attempts to identify content compounds were almost 100 years ago. In this review we discuss the present state of knowledge in the chemistry of substances of Commiphora spp.

\section{INTRODUCTION}

Myrrh and the similar but lower quality opopanax are the hardened, resinous exudates obtained from trees of certain Commiphora species of the Burseraceae family. Myrrh and opopanax oils are occasionally used as flavouring agents. Somalia and Ethiopia are by far the largest producers of the two resins. Northern Somalia is the world's largest source of incense and myrrh, which are forestry products. Aromatic flora, producing frankincense and myrrh, are indigenous to the mountain slopes. Somalia supplies most of the world's myrrh and opopanax (about 1500 tonnes in 1987). The People's Republic of China is the largest market for all two resins, mainly for use in traditional medicines. In early 1994, clean Somali myrrh was available at US $\$ 5 / \mathrm{kg}$. Somali opopanax was priced at US \$3.50/ kg (clean) and US \$3.00/ kg (natural).

Commiphora species are small trees or shrubs with short, thorny branches. True myrrh is produced by C. myrrha, a variable species found in southern Arabia and northeast Africa (chiefly Somalia) as far south as northeast Kenya. Other resin-producing Commiphora occur in southern Arabia, Sudan, Ethiopia, Eritrea, Somalia and Kenya. C. erythraea and C. kataf, the main sources of opopanax, are abundant in many parts of southern Arabia, Somalia, eastern Ethiopia and Kenya.

In Arabic the word murr means "bitter", it has been used throughout history in incense and as a perfume. It is said that the Greek soldiers would not go into battle without a poultice of myrrh to put on their wounds. It is often used in toothpastes and in the perfume industry. It tends not to dissolve very well in water however.

Myrrh consists of water-soluble gum, alcohol-soluble resins and volatile oil. The gum contains polysaccharides and proteins, while the volatile oil is composed of ster- oids, sterols and terpenes. Myrrh's characteristic odor is derived from furanosesquiterpenes.

Since Bible times it has been used as a medicine and wound dressing and has been closely associated with the health and purification rituals of women. It was first described in the Chinese medical literature. The use of myrrh medicinally was recorded in China in A.D. 600 during the Tang Dynasty. Myrrh is used today in Chinese medicine to treat wounds, relieve painful swelling, and to treat menstrual pain due to blood stagnation. Myrrh is called mo yao in China. It has long been used in the Ayurvedic system of medicine.

Commiphora opobalsamum balm is the thickened gum from the juice of the balsam tree, which was abundant in Judea. It is native to southern Arabia and Abyssinia, was cultivated on the plains of Jericho and the Jews believed it was planted by King Solomon. According to history the Queen of Sheba brought balm to Solomon on the occasion of her visit. Balm was rare and costly when exhibited in Rome for all people to see. After the conquest of Judah, it was brought by Pompey for display. When Vespasian destroyed Jerusalem, balm was among his spoils. Balm was the emblem of Palestine and newly cultivated shrubs were protected by sentries.

\section{General}

On this place we must mention the most known Commiphoras, namely Commiphora myrrha (Nees) Engl., true myrrh, officinal myrrh, Heera Bol tree; C. myrrha (Nees) Engler var molmol Engler (C. molmol Engl. ex Tschirch), Somalian myrrh; Commiphora abyssinica (Berg) Engler (syn. Commiphora madagascarensis Jacq.), Arabian myrrh, Abyssinian myrrh; Commiphora africana (A. Rich.) Eng1., myrrh, African bdelium; Commiphora guidottii Chiov., sweet myrrh, habag-hady (name in Somalia); 
Commiphora mukul (Hook ex Stocks) Engl. (Commiphora wightii (Arnott.) Bhanol.), guggul, guggulu, false myrrh; Commiphora opobalsamum ( C. gileadensis (L.) Christ.; Balsamodendron meccansis Gled.), balm of the Mecca; Commiphora erythraea (Ehrenb.) Engl., opopanax (originally Hemprichia erythraea); Commiphora erythraea var. glabrascens, opopanax and Commiphora kataf (Forssk.) Engl., african opopanax.

Pernet mention the places of known Commiphoras ${ }^{1}$ : Commiphora Jacq. - over 200 species around Read Sea in East Africa, 20 species in Madagascar and 6 in India; C. abyssinica Engl., "myrrh" -Ethiopia and Jemen; $C$. agallocha Eng. - India; C. africana - Ethiopia and subsaharian Africa

C. aprevali (Baill) Guill. - Madagascar; C. Boiviniana Engl. - tropic Africa; C. charten Birdw. - tropic Africa; $C$. erythraea Eng1., "opopanax" or "bisabol” - mediteranean region and Ethiopia; C. kataf Engl., "african opopanax" - Arabia; C. merkeri Engl. - tropic Africa; C. mukul Engl. - India; C. myrrha Engl., "officinal myrrh" - Arabia and Lybia and Somalia; C. opobalsamum, "balm of the Mecca" - Arabia and Somalia; C. Pervilleana Engl., "matambelona" - Madagascar; C. pilosa Engl. - tropic Africa; $C$. pyracanthoides (syn. C. glandulosa Schinz.) - tropic Africa; C. Roxburgii Alston (syn. C. agalocha); C. Schimperi Engl. - Ethiopia and Erythrea; C. simplicifolia H. Perr., "sangathy" - Madagascar; C. ugogensis Engl. -tropical Africa and C. Zimmermannii Engl. - tropical Africa.

The following new species were described by Thulin²: Commiphora arenaria from bushland on sand in south-central Somalia, C. gardoensis from limestone slopes in the Qardho area in north-eastern Somalia, C. stellatopubescens from bushland on limestone outcrops or stony ground in the Hiiraan Region in south-central Somalia, C. spinulosa from limestone rocks on the escarpment along the Gulf of Aden in northeastern Somalia, C. lobatospathulata from bushland on sand in central and southcentral Somalia, $C$. quercifoliola from bushland on shallow soil over limestone near Eil in north-eastern Somalia, $C$. chiovendana from bushland in northern and central Somalia, C. multifoliolata from limestone hills and ridges in south-western Somalia, C. murraywatsonii from limestone outcrops near Hobyo in central Somalia, and $C$. kucharii from bushland on shallow soils over limestone in central and southern Somalia.

The next publication goes further to inform as about present state of distribution of Commiphora spp. (ref. ${ }^{3}$ ) Commiphora myrrha is the chief source of myrrh today, but $C$. erythraea was the principal source of ancient and classical time. A number of oleo-gum-resins called bdelliums are produced in Arabia and Somalia from various species of Commiphora and resemble myrrh; these were probably counted as myrrh in classical times and are probably used for adulteration today. The "perfumed bdellium" (opopanax or bisabol myrrh) is from C. erythraea. Common myrrh (or hirabol myrrh) is obtained from $C$. myrrha (Nees) Engl. Abyssinian myrrh is obtained from C. madagascariensis Jacq. (C. abyssinica).
Other species sometimes passing as myrrh or bdellium include $C$. africana (A. Rich.) Engl., C. anglosomaliae Chiov., C. gileadensis (L.) Christ. (C. opobalsamum (L.) Engl., C. hildebrandtii Engl., C. kataf (Forsk.) Engl., $C$. molmol Engl. ex Tschirch (Somalian myrrh), C. mukul (Hook.) Engl., and C. schimperi (Berg) Engl. Myrrh has been employed for incense and embalming since ancient times. Myrrh is employed by perfumers as an absolute, oil, or resinoid. Myrrh is included in the formulations of a number of modern perfumes, is used by many herbalists as an astringent for the mucous membranes of the mouth and throat.

\section{Myrrh}

As mentioned by Guenther ${ }^{4}$, myrrh (also called heerabol-myrrh or bitter myrrh) is gum-resin obtained from several species of Commiphora (fam. Burseraceae), notably C. abyssinica (Berg) Engler, C. schimperi (Berg) Engler, and $C$. myrrha (Nees) Engler var molmol Engler. Genus Commiphora comprises more than 200 species, all native to Africa, Arabia, Madagascar and India.

In order to collect gum, the natives make incisions into the bark, causing the exudation of a yellowish oleoresin. Exposed to the air, this dries, hardens and turns reddish-brown.

Myrrh is partly soluble in ethanol ( $30 \%$ alcoholsoluble material) and is also partly soluble in water and in ether. Since antiquity myrrh has served as a constituent of incense. Oil of myrrh is a valuable ingredient in perfumes (balsamic, heavy odour).

The chemistry of myrrh oil was first investigated by Lewinsohn (Arch. Pharm. 244, 412, 1906), von Friedrichs (Arch. Pharm. 245, 432, 1907) and Trost and Doro (Ann. chim. Applicata 26, 126, 1936). These authors found the following constituents: $\alpha$-pinene 1, dipentene $[=( \pm)$-limonene $]$, limonene 2 , cuminaldehyde 3 , cinnamic aldehyde 4, eugenol 5, m-cresol 6, heerabolene (probably tricyclic sesquiterpene), cadinene (?), a sesquiterpene (?), a bicyclic sesquiterpene $\left(\mathrm{C}_{15} \mathrm{H}_{24}\right)$, a tricyclic sesquiterpene $\left(\mathrm{C}_{15} \mathrm{H}_{24}\right)$, formic acid, acetic acid, myrrholic acid $\left(\right.$ ?, $\left.\mathrm{C}_{16} \mathrm{H}_{21} \mathrm{O}_{3} . \mathrm{COOH}\right)$ and palmitic acid.

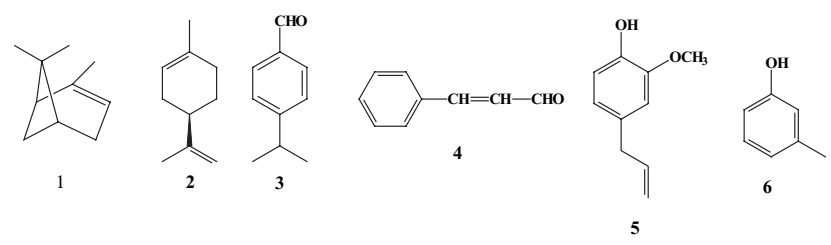

Later was from "Commiphora myrrha" resin isolated the following compound - isolinalyl acetate 7, 3-epi-lupenyl acetate 8, lupeone 9, 3-epi- $\alpha$-amirin 10, $\alpha$-amirone 11, acetyl $\beta$-eudesmol 12 and a sesquiterpenoid lactone ${ }^{5}$. 


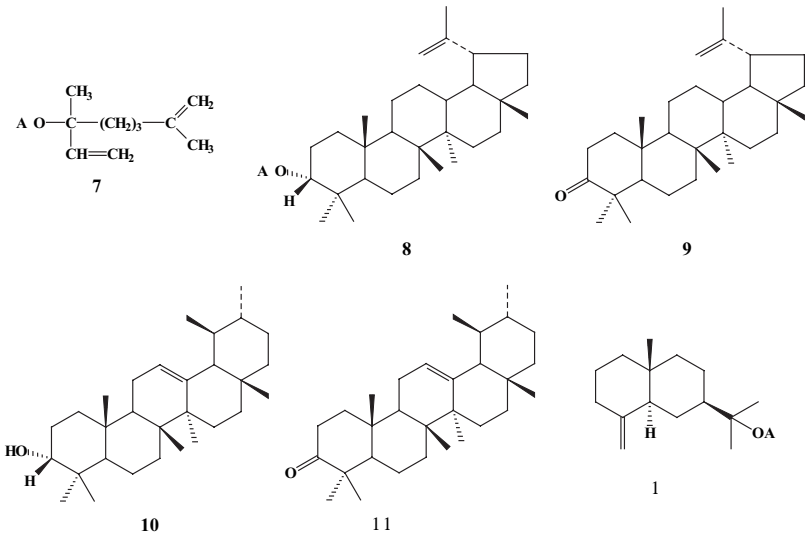

Another laboratory reported on the following in oil of myrrh $^{6}$ : $11.9 \%$ curzerene 13 (ref. ${ }^{7-10}$ ), 12.5\% furanoeudesma-1,3-diene 14, 1.2\% 1,10(15)-furanodien-6one 15 (ref. $^{11,12}$ ), 3.5\% lindestrene $\mathbf{1 6}$ (ref. $^{13-15}$ ), $11.7 \%$ curzerenone 17 (ref. ${ }^{16,17}$ ), 0.4\% furanodien-6-one 18, 1.1\% dihydropyrocurzerenone 19, $1.5 \%$ 3-methoxy-10(15)-dihydrofuranodien-6-one 20, 0.1 \% 3-methoxyfuranoguaia-9en-8-one 21, 0.2\% 2-methoxy-4,5-dihydrofuranodien-6-one 22, and $0.9 \%$ 3-methoxy-10-methylenefuranogermacra-1en-6-one 23. These authors also reported that a mixture of furanoeudesma-1,3-diene and lindestrene possessed a typical myrrh odor, while dihydropyrocurzerenone possessed a resinous myrrh odor; the latter compound best represented the odor of myrrh by itself.

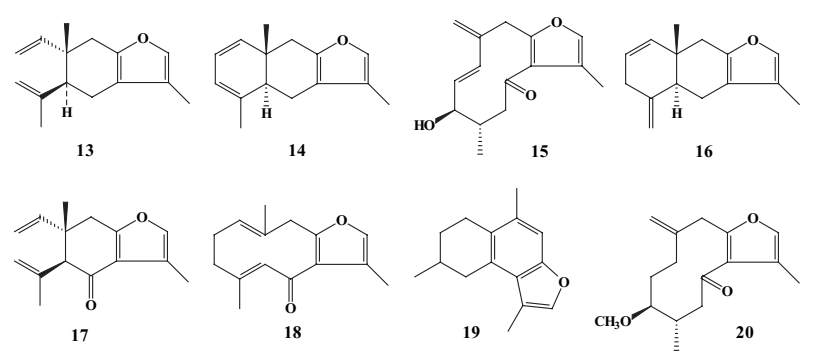<smiles>COC1CC2C(C)=CC(=O)C3C(C)=COC3C2C1C</smiles><smiles>C/C=C\Cc1occ(C)c1C(=O)C[C@H](C)C[C@H](C)CO</smiles>

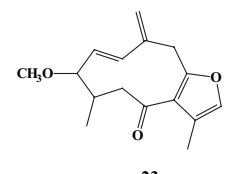

2-acetoxyfuranodiene $\mathbf{2 4}$ and 2-methoxyfuranodiene 25 were isolated from chloroform extract of ground myrrh (commercially available) with the help of flash chromatography by Monti ${ }^{18}$. The absolute configuration of these compounds was determined.

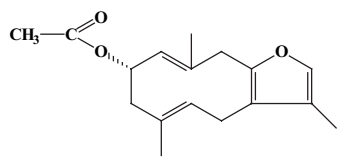

24

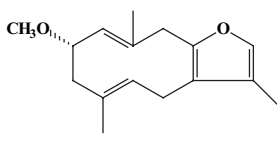

25

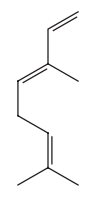

Ma et al. (ref. ${ }^{19}$ ) described an analytical supercritical fluid extraction (SFE) system and its application to GC/ MS of frankincense and myrrh, Chinese medicines. The result shows that analytical SFE is a more afficient technique for investigating Chinese medicine compounds. In addition the information generated supplements to the available literature on title medicines and revealed its potential application in the compound study of the Chinese herbal medicine.

The constituents of the supercritical fluid extraction and the steam distillate of myrrh and Curcuma zedoaria, two Chinese herbal medicines with the help of GC/ITD studied $\mathrm{Yu}^{20}$. Fourty one and 45 compounds were identified, respectively, in myrrh and C. zedoaria which were mainly sesquiterpenoids and furanose sesquiterpenoids. The feature of their ion trap mass spectrum is also discussed.

The purity of myrrh batches of various origin were tested according to the DAB $10\left(10^{\text {th }}\right.$ German pharmacopeia $)^{21}$. The contents and structures of the gum fractions were identical despite differences in the essential oil fractions. The raw gums were heterodisperse systems and contained $\sim 70 \%$ 4-methyl-glucuronogalactone protein. Therefore, a classification of myrrh in the group of arabinogalactan proteins is no longer correct.

Wang $^{22}$ analyzed by capillary GC/MS and GC/FTIR the chemical components of the essential oil of myrrh obtained from Kenya. The oil contained monoterpenes and sesquiterpenes. Researchers identified sixteen main constituents.

The constituents of essential oil in myrrh and gum opopanax were analyzed by GC-MS. Fifteen compounds in Myrrh and 33 compounds in gum opopanax were identified and their percent content was detected. The main constituents of myrrh was furanoeudesma-1,3-diene 14 and the main constituent of gum opopanax was trans$\beta$-ocimene 26 (ref. ${ }^{23}$ ).

With the help of Fourier-transform Raman spectroscopy myrrh can be easily distinguished from frankincense and different colored specimens can be identified. Relative proportions of compounds in a sample, and hence the color, is dependent on the climatic and environmental conditions. Myrrh shows more variety in its color (myrrh red, myrrh orange, myrrh yellow, myrrh brown and myrrh black) and in the observed Raman spectra. The common bands which occur for myrrh samples are not specific enough for identification of individual colored myrrh samples ${ }^{24}$. Such non-destructive methods of analysis are preferred by archeologists.

Tree resins have been used extensively throughout history. Tree resins are composed of terpene and terpenoid compounds, and diterpenoids and triterpenoids are the most common. Diterpenoids and triterpenoids have not been found together in a resin; thus, resins from each group have differing properties. Frankincense and myrrh are resins that contain triterpenoid components. Fourier transform-Raman spectrometry has potential as a nondestructive and noninvasive means of identifying both ancient and modern resin samples in situ. Because of that it has advantages particularly in the field of archeological sciences. The spectra of myrrh are very different than those of any of the other resins examined. Myrrh 
cannot be mistaken for any other resin because it has a high enough proportion of gum to make its spectra unlike those of any of the resins examined by the authors. The spectra of myrrh are easily distinguished from those of the diterpenoid and triterpenoid resins ${ }^{25}$.

\section{Commiphora myrrha}

The isolation and characterization of D-galactose 27, L-arabinose 28, and 4-methyl D-glucuronic acid 29 as component of gum myrrh (Commiphora myrrha Holmes) are described.

The gum myrrh has been used as incense for many centuries. In more recent times, the gum has found medical usage as an antiseptic, the tincture being applied to inflammatory and ulcerated conditions of the throat and mouth.

Extraction with $90 \%$ aqueous alcohol the resins are largely removed and the crude polysaccharides are obtained. After hydrolysis at least 15 aminoacids were detected and in fractions D-galactose, L-arabinose, and 4-methyl D-glucuronic acid (in proportions $4: 1: 3$ ) were identified $^{26}$.
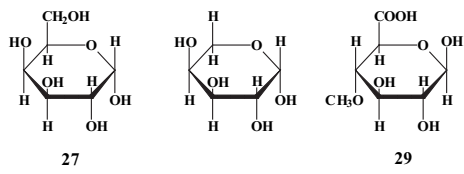

Hydrolysis of purified polysaccharides of gum myrrh (Commiphora myrrha Holmes) gave high yields of a mixture of neutral sugars and acidic oligosaccharides. The latter after isolation and purification gave 1:6 mixture of two aldobiuronic acids, identified as 6-O-(4-O-methyl- $\beta$ D-glucuronosyl)-D-galactose 30 and 4-O-(4-O-methyl- $\alpha$ D-glucuronosyl)-D-galactose 31 ( ref. $^{27}$ ).
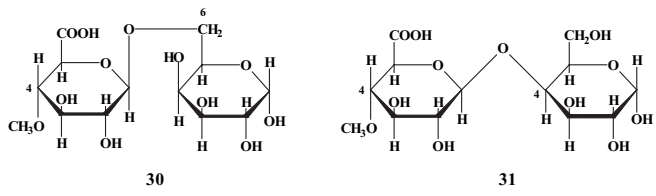

From Commiphora myrrha sesquiterpen commiferin 32 was isolated ${ }^{28}$.

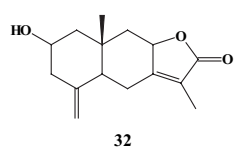

Chromatography of hexane extracts of Commiphora erythraea Engler gum, the source of opopanax oil, led to isolation and identification of known furanodienone $\mathbf{1 8 .}$ The same extraction of Commiphora myrrh (Nees) Engler, the source of myrrh oil, resulted in two new furanosesquiterpenoids, 2-O-acetyl-8,12-epoxygermacra1(10),4,7,11-tetraene 24 and 2-O-methyl-8,12-epoxygermacra-1(10),4,7,11-tetraene 25 (ref. $^{29}$ ). Both gums were collected in Kenya.

The eight samples of resin collected in Kenya and attributed to Commiphora myrrha (one of them called
C. ellenbeckii) and Commiphora holtziana have been examined. These have yielded a wide range of sesquiterpenes, notably furanosesquiterpenes based on eudesmane, elemane and germacrene (Table 1). The distribution of these compounds is discussed in relation to the collection and commerce of myrrh-like resins in Kenya. The simple sesquiterpenes identified in C. holtziana were comparable to those recorded for opopanax oil ${ }^{30}$.

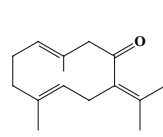

33

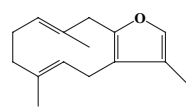

36

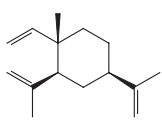<smiles>C=CC1(C)CCC(C(C)(C)C)CC1C(=C)C</smiles>

42

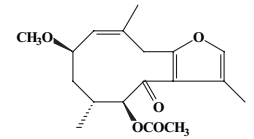

34
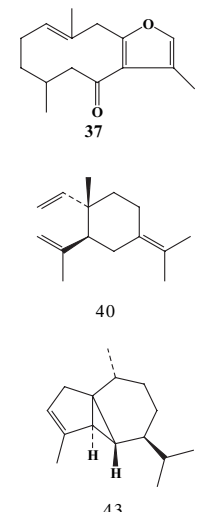

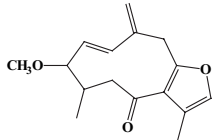

35
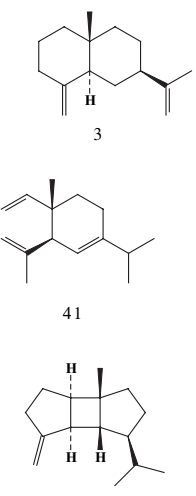

44
Table 1. Major sesquiterpenes identified from Commiphora myrrha and C. holtziana.

\begin{tabular}{|c|c|c|}
\hline Components & C. myrrha & C. holtziana \\
\hline germacrone $^{\text {a }} 33$ & + & + \\
\hline C 22 & - & + \\
\hline D 34 & - & + \\
\hline В 35 & - & + \\
\hline furanodiene $^{\text {b, c }} 36$ & + & - \\
\hline 2-methoxyfuranodiene $\mathbf{2 5}$ & + & - \\
\hline 4,5-dihydrofuranodiene-6-one 37 & + & + \\
\hline$\beta$-selinene 38 & - & + \\
\hline lindestrene 16 & $+*$ & + \\
\hline furanoeudesma-1,3-diene $\mathbf{1 4}$ & + & - \\
\hline$\beta$-elemene 39 & + & $+* *$ \\
\hline$\gamma$-elemene $\mathbf{4 0}$ & + & + \\
\hline$\delta$-elemene 41 & - & + \\
\hline elemol 42 & - & + \\
\hline isofuranogermacrene $^{\mathrm{c}} \mathbf{1 3}$ & $+* *$ & - \\
\hline curzerenone $\mathbf{1 7}$ & + & + \\
\hline$\alpha$-cubebene 43 & + & - \\
\hline$\beta$-bourbonene 44 & - & + \\
\hline
\end{tabular}

* found in all samples, ** found in most of the samples $\mathrm{a}^{31,32}, \mathrm{~b}^{33}, \mathrm{c}^{9}$

$B=$ (1E)-3-methoxy-8,12-epoxygermacra-1,7,10,11-tetraen-6one

$\mathrm{C}=\left(1(10) \mathrm{E}, 2 \mathrm{R}^{*}, 4 \mathrm{R}^{*}\right)$-2-methoxy-8,12-epoxygermacra1(10), 7,11-trien-6-one

$\mathrm{D}=$ rel-2R-methyl-5S-acetoxy-4R-furanogermacr-1(10)Zen-6-one 
Gum resins of Commiphora myrrha (Nees) Engler are important commercial products (fragrant oil) in Kenya, Ethiopia and Somalia. Hexane-soluble viscosous oil is responsible for the characteristic odor of the gum. With the help of high-performance liquid chromatography the oil mixture was separated into pure compounds. These were identified with GC/MS as known furanosesquiterpenoids isofuranogermacrene (= isogermafurene) 13, lindestrene 16, furanoeudesma-1, 3-diene $\mathbf{1 4}$ and furanodiene (= isofuranodiene) 36. Based on the presence or absence of these compounds, it is possible to differentiate or detect adulteration of commercial gum resins labeled as $C$. myrrh myrrh oil from C. erythraea opopanax oil ${ }^{34}$.

The best quality of myrrh is obtained from the species Commiphora myrrha (Nees) Engl. This myrrh one can find also under synonyms $C$. rivae Engl, $C$. coriacea Engl., C. molmol (Engl.) Engl. and C. habessinica (Berg.) Engl. var. grossedentata Chiov. Myrrh is collected from other species of Commiphora as well. These include: $C$. Africana (A. Rich.) Engl., C. erythraea (Ehrenb.) Engl., $C$. gileadensis (L.) C. Chr., C. habessinica (Berg) Engl., $C$. hodai Sprague, C. kua (R. Br. Ex Royle) Vollesen, $C$. quadricinta Schweinf., C. schimperi (Berg) Engl. and $C$. truncate Engl.

Chemical investigation of Commiphora has been done on some Kenyan species occurring also in Ethiopia. The main volatile components include monoterpenes (limonene 2, p-cymene 45, $\alpha$-terpineol 46) and sesquiterpenes ( $\beta$-bisabolene 47$)\left(\right.$ ref. $^{35}$ ).

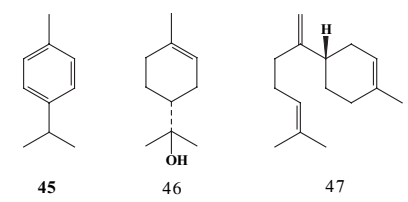

A furanoeudesmane, $5 \alpha \mathrm{H}-8,12$-furanoeudesma-1,3diene (furanoeudesma-1,3-diene) 14, was synthetised ${ }^{36}$. A natural product isolated first from Commiphora molmol and later from Commiphora myrrh oil was synthetised enantiomerically pure.

The resin of Commiphora myrrha, collected in Ethiopia, was extracted with aqueous ethanol and petroleum ether. Following partition and column chromatography gave previously reported antihyperglycemic compounds, furanoeudesma-1,3-diene $\mathbf{1 4}$ and 2-O-acetyl-8,12-epoxygermacra-1(10), 4,7,11-tetraene 24 (ref. ${ }^{37}$ ).

Commiphora myrrha Engl., a plant found in some African and Asian countries (as Kenya, India or People's Republic of China), yields a yellow nonvolatile gum resin (myrrh), which has been used as a food additive, a fragrance, and a traditional medicine. Authors here reported isolation of two new sesquiterpenoids as well as four known derivatives from a Chinese sample of C. myrrha. After exudates extraction with ethyl acetate and column chromatography on silica gel four already known compounds were eluted, namely curzerenone $\mathbf{1 7}$, furanogermacra-1(10)Z,4Z-dien-6-one 48, rel-3R-methoxy-4S-furanogermacra-1E,10(15)-dien-6-one 49 and
Table 2. Relative concentration (\%) of components of the hydrodistillates of Commiphora sphaerocarpa, $C$. holtziana, C. kataf and C. myrrha (GC-MS).

\begin{tabular}{|c|c|c|c|c|}
\hline Components & C.s. & C. $h$. & C. $k$. & C. $m$. \\
\hline$\alpha$-pinene 1 & 0.6 & - & - & - \\
\hline myrcene 52 & 1.5 & - & - & - \\
\hline 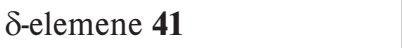 & - & - & 0.4 & 2.1 \\
\hline$\alpha$-copaene 53 & 5.3 & 1.1 & $\operatorname{tr}$ & 0.2 \\
\hline$\beta$-bourbonene 44 & - & - & 0.7 & 1.2 \\
\hline$\beta$-ylangene 54 & - & - & - & 0.3 \\
\hline$\beta$-elemene 39 & 6.7 & 5.0 & 6.4 & 8.7 \\
\hline$\alpha$-gurjunene 55 & 7.0 & - & 0.5 & - \\
\hline trans-caryophyllene 56 & 1.0 & - & 0.5 & 1.3 \\
\hline$\gamma$-elemene $\mathbf{4 0}$ & - & - & - & 1.1 \\
\hline$\alpha$-humulene $\mathbf{5 7}$ & 0.7 & 0.4 & 0.7 & 0.6 \\
\hline alloaromadendrene $\mathbf{5 8}$ & - & - & - & 0.2 \\
\hline$\gamma$-muurolene 59 & - & - & - & 0.2 \\
\hline germacrene $\mathrm{D}^{\mathrm{d}} \mathbf{6 0}$ & - & 23.0 & 9.0 & 3.2 \\
\hline$\beta$-selinene 38 & 8.0 & 7.0 & 2.0 & 0.6 \\
\hline$\alpha$-selinene 61 & 11.0 & - & 2.4 & 0.5 \\
\hline bicyclogermacrene ${ }^{\mathrm{e}} 62$ & - & - & - & 0.2 \\
\hline$\alpha$-guaiene 63 & 6.0 & - & - & - \\
\hline$\gamma$-cadinene 64 & 4.7 & - & 0.3 & 1.2 \\
\hline$\delta$-cadinene 65 & 2.1 & 1.1 & 1.0 & 0.4 \\
\hline furanodiene 36 & - & - & - & 19.7 \\
\hline isofuranogermacrene $\mathbf{1 3}$ & - & - & - & 2.0 \\
\hline elemol 42 & - & - & - & 0.2 \\
\hline germacrene-B 66 & 5.0 & 7.2 & 7.1 & 4.3 \\
\hline furanoeudesma-1,4-diene $\mathbf{6 7}$ & - & - & - & 1.2 \\
\hline furanoeudesma-1,3-diene $\mathbf{1 4}$ & - & - & - & 34.0 \\
\hline lindestrene 16 & - & - & - & 12.0 \\
\hline$\beta$-eudesmol 68 & - & - & 2.0 & - \\
\hline T-cadinol 69 & 7.0 & - & - & 1.6 \\
\hline 2-methoxyfuranodiene 25 & - & - & - & 2.1 \\
\hline 2-acetoxyfuranodiene 24 & - & - & - & $\operatorname{tr}$ \\
\hline $\begin{array}{l}\text { curzerenone } 17 \text { furanodi- } \\
\text { enone } \mathbf{1 8}\end{array}$ & 13.0 & 6.1 & 1.0 & - \\
\hline germacrone $\mathbf{3 3}$ & 1.0 & 2.0 & 3.0 & - \\
\hline A 51 & 2.0 & 11.4 & 22.0 & - \\
\hline dihydropyrocurzerenone 19 & 1.2 & - & 3.4 & - \\
\hline B 35 & 2.4 & 1.0 & $\operatorname{tr}$ & - \\
\hline C 22 & 3.0 & 3.1 & 13.0 & - \\
\hline
\end{tabular}

$\mathrm{d}^{40,41}, \mathrm{e}^{42,43}$

$\mathrm{A}=$ (1E)-8,12-epoxygermacra-1,7,10,11-tetraen-6-one

$\mathrm{B}=$ (1E)-3-methoxy-8,12-epoxygermacra-1,7,10,11-tetraen-6one

$\mathrm{C}=\left(1(10) \mathrm{E}, 2 \mathrm{R}^{*}, 4 \mathrm{R}^{*}\right)-2$-methoxy-8,12-epoxygermacra1(10), 7,11-trien-6-one 
Table 3. Relative concentration (\%) of components in Commiphora myrrha var. molmol essential oil.

\begin{tabular}{|c|c|}
\hline Compound & $\%$ \\
\hline$\delta$-elemene 41 & 0.5 \\
\hline$\beta$-bourbonene 44 & 0.6 \\
\hline$\beta$-elemene 39 & 8.4 \\
\hline$\beta$-caryophyllene 56 & 0.7 \\
\hline$\gamma$-elemene $\mathbf{4 0}$ & 2.6 \\
\hline$\alpha$-humulene 57 & 0.3 \\
\hline dehydroaromadendrane $\mathbf{7 0}$ & 0.1 \\
\hline 9-epi-caryophyllene $\mathbf{7 1}$ & 0.4 \\
\hline$\gamma$-muurolene $\mathbf{5 9}$ & 0.3 \\
\hline alloaromadendrene $\mathbf{5 8}$ & 1.7 \\
\hline curzerene $\mathbf{1 3}$ & 40.1 \\
\hline$\gamma$-cadinene 64 & 0.8 \\
\hline$\delta$-cadinene 65 & 0.3 \\
\hline$\beta$-sesquiphellandrene 72 & 0.2 \\
\hline selina-3,7(11)-diene 73 & 0.2 \\
\hline elemol 42 & 0.2 \\
\hline caryophyllene alcohol 74 & 0.4 \\
\hline caryophyllene oxide 75 & 0.2 \\
\hline cis- $\beta$-elemenone 76 & 0.8 \\
\hline furanoeudesma-1,3-diene $\mathbf{1 4}$ & 15.0 \\
\hline$\gamma$-eudesmol 77 & 2.7 \\
\hline furanodiene 36 & 1.1 \\
\hline 7-epi- $\alpha$-eudesmol 78 & 2.2 \\
\hline $\begin{array}{l}\text { 2-O-methyl-8,12-epoxy- germacra- } \\
\text { 1(10),4,7,11-tetraene, isomer I* } 25\end{array}$ & 0.5 \\
\hline $\begin{array}{l}\text { 2-O-methyl-8,12-epoxy- germacra- } \\
\text { 1(10),4,7,11-tetraene, isomer II* } 25\end{array}$ & 3.9 \\
\hline 2-hydroxyfuranodiene 79 & 0.2 \\
\hline 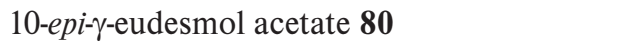 & 0.3 \\
\hline $\begin{array}{l}\text { 2-O-acetyl-8,12-epoxy-germacra-1(10),4,7,11- } \\
\text { tetraene, isomer I* } \mathbf{2 4}\end{array}$ & 6.5 \\
\hline $\begin{array}{l}\text { 2-O-acetyl-8,12-epoxy-germacra-1(10),4,7,11- } \\
\text { tetraene, isomer II* } \mathbf{2 4}\end{array}$ & 0.3 \\
\hline
\end{tabular}

* correct isomeric form was not determined

rel-2R-methoxy-4R-furanogermacr-1(10)E-en-6-one 22. The structures of the new compounds, rel-1S,2S-epoxy4R-furanogermacr-10(15)-en-6-one $\mathbf{5 0}$ and rel-2R-methyl5S-acetoxy-4R-furanogermacr-1(10)Z-en-6-one 34, were elucidated by spectroscopic methods and with the aid of molecular modeling ${ }^{38}$.

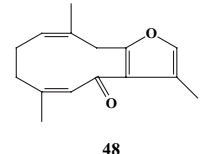

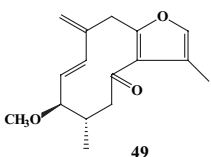

49

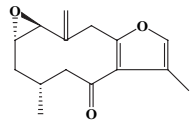

50
The genus Commiphora comprises over 150 species, most of which are confined to Eastern Africa, with few species also occurring in Arabia and India. The composition of true myrrh, derived from $C$. myrrha was compared with some of its adulterans ( $C$. sphaerocarpa Chiov., $C$. holtziana Engl. and C. kataf(Forssk. Engl.) (Table 2). The petrolether extract of $C$. sphaerocarpa gave after chromatography over silica six compounds. One of them, (1E)8,12-epoxygermacra-1,7,10,11-tetraen-6-one $\mathbf{5 1}$, is a new furanosesquiterpene ${ }^{39}$.

Analysis of true myrrh failed to confirm presence of curzerenone, furanodienone, (1E)-3-methoxy-8,12-epoxygermacra-1,7,10,11-tetraen-6-one and (1(10)E,2 R*,4R*)-2methoxy-8,12-epoxygermacra-1(10),7,11-trien-6-one.
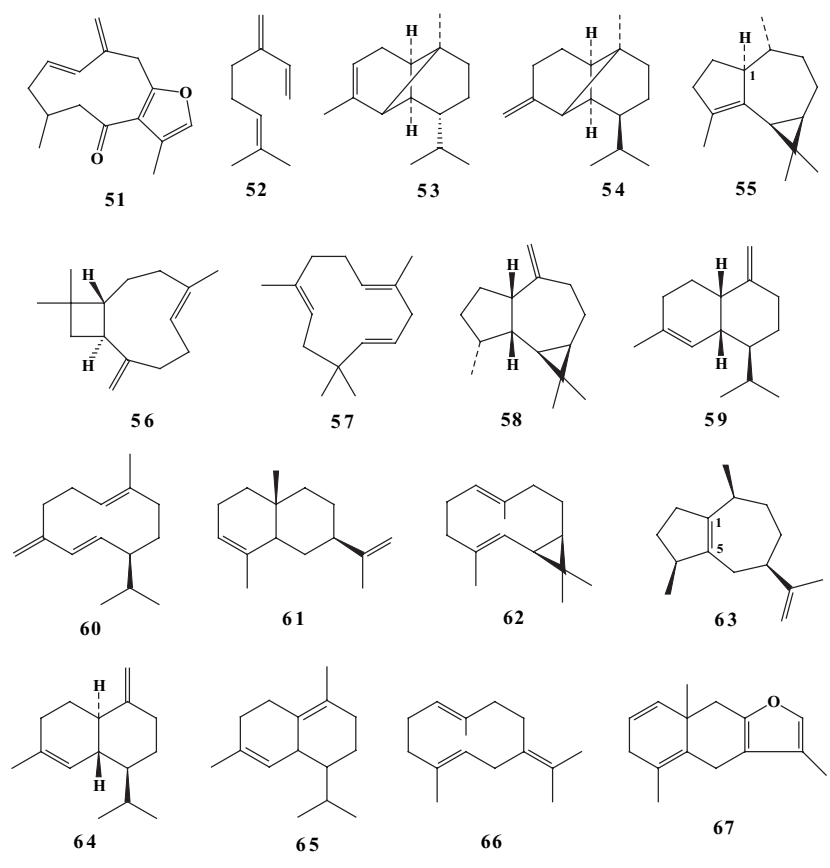

67<smiles>C=C1CCCC2(C)CCC(C(C)(C)O)CC12</smiles>

68<smiles>CC1=CC2C(CC1)C(C(C)C)CCC2(C)O</smiles>

Hydrodistillation of the crushed air-dried oleo-gum resin of Commiphora myrrha (Nees) Engl. var. molmol yielded $3.1 \%$ of oil. The chemical composition of the essential oil was examined using GC and GC/MS (Table 3). The relative percentage of the 32 compounds (about $94.6 \%$ of the oil) identified in this oil was calculated from the total ion chromatogram ${ }^{44}$.
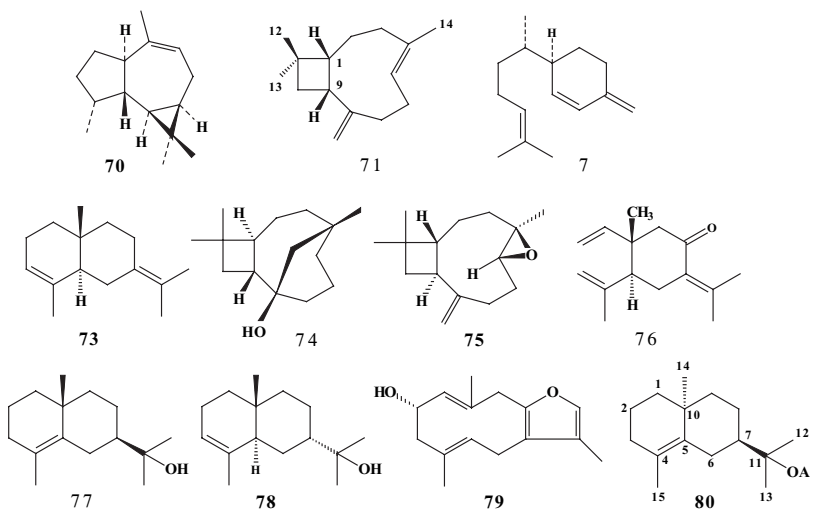
Table 4. The composition of Ethiopian Commiphora essential oils.

\begin{tabular}{|c|c|c|}
\hline Compound & C. myrrha & C. guidotti \\
\hline limonene 2 & - & 0.2 \\
\hline (Z)- $\beta$-ocimene 26 & - & 0.7 \\
\hline (E)- $\beta$-ocimene 26 & - & 33.0 \\
\hline$\delta$-elemene 41 & 2.1 & - \\
\hline$\alpha$-copaene 53 & 0.2 & - \\
\hline (E)- $\beta$-ocimene epoxide 81 & - & 0.3 \\
\hline$\beta$-bourbonene 44 & 1.2 & - \\
\hline cis- $\alpha$-bergamotene $\mathbf{8 2}$ & - & 0.3 \\
\hline 1-methyl-4-acetylcyclohex-1-ene $\mathbf{8 3}$ & - & 0.5 \\
\hline$\beta$-ylangene 54 & 0.3 & - \\
\hline$\alpha$-bergamotene 82 & - & 3.0 \\
\hline$\alpha$-santalene 84 & - & 15.8 \\
\hline trans- $\beta$-bergamotene $\mathbf{8 5}$ & - & 6.6 \\
\hline$\beta$-elemene 39 & 8.7 & 0.1 \\
\hline 6-methyl-3,5-heptadiene-2-one 86 & - & 0.4 \\
\hline$\beta$-caryophyllene 56 & 1.3 & - \\
\hline epi- $\beta$-santalene 87 & - & 0.6 \\
\hline$\gamma$-elemene $\mathbf{4 0}$ & 1.1 & - \\
\hline alloaromadendrene $\mathbf{5 8}$ & 0.2 & - \\
\hline (Z)- $\beta$-santalene $\mathbf{8 8}$ & - & 0.4 \\
\hline nonanol & - & 0.2 \\
\hline (Z)- $\beta$-farnesene 89 & - & 0.8 \\
\hline (E)- $\beta$-farnesene 89 & - & 0.8 \\
\hline$\alpha$-humulene 57 & 0.6 & - \\
\hline$\gamma$-muurolene 59 & 0.2 & - \\
\hline germacrene D 60 & 3.2 & 1.6 \\
\hline cis- $\alpha$-bisabolene 99 & - & 22.2 \\
\hline$\beta$-selinene $\mathbf{3 8}$ & 0.6 & - \\
\hline$\alpha$-selinene 61 & 0.5 & - \\
\hline bicyclogermacrene 62 & 0.2 & - \\
\hline decanol & - & 1.2 \\
\hline$\delta$-cadinene 65 & 0.4 & 0.2 \\
\hline$\gamma$-cadinene 64 & 1.2 & - \\
\hline $\begin{array}{l}\text { 2,6-dimethyl-3(E),5(E),7-octatrien- } \\
\text { 2-ol } 90\end{array}$ & - & 0.7 \\
\hline germacrene B 66 & 4.3 & - \\
\hline furanodiene 36 & $19.7 *$ & 0.1 \\
\hline elemol 42 & 0.2 & - \\
\hline furanoeudesma-1,4-diene $\mathbf{6 7}$ & 1.2 & - \\
\hline furanoeudesma-1,3-diene $\mathbf{1 4}$ & $34.0 *$ & - \\
\hline lindestrene $\mathbf{1 6}$ & $12.0 *$ & - \\
\hline T-cadinol 69 & 1.6 & - \\
\hline (E)- $\alpha$-santalal 91 & - & 0.4 \\
\hline 2-methoxyfuranodiene 25 & 2.1 & - \\
\hline
\end{tabular}

* Confirmed by co-injection and NMR.
Most previous reports were based on materials obtained from markets rather than from properly identified trees. Authors here described the results on the volatile oils (obtained by hydrodistillation) of resin collected in Ethiopia from two Commiphora spp. (C. myrrha and $C$. guidotti). The oils were analysed by GC/MS (Table 4). Using ${ }^{1} \mathrm{H}$ - and ${ }^{13} \mathrm{C}$ and $\mathrm{GC} / \mathrm{MS}$ analysis authors established in their previous work the absence of oxygenated furanosesquiterpenes, curzerenone and furanodienone, and other C-6 oxygenated furanosesquiterpenes in the essential oil as well as extracts of myrrh ${ }^{45}$. The source of adulterant resins coming mainly from $C$. sphaerocarpa, $C$. holtziana and C. kataf.
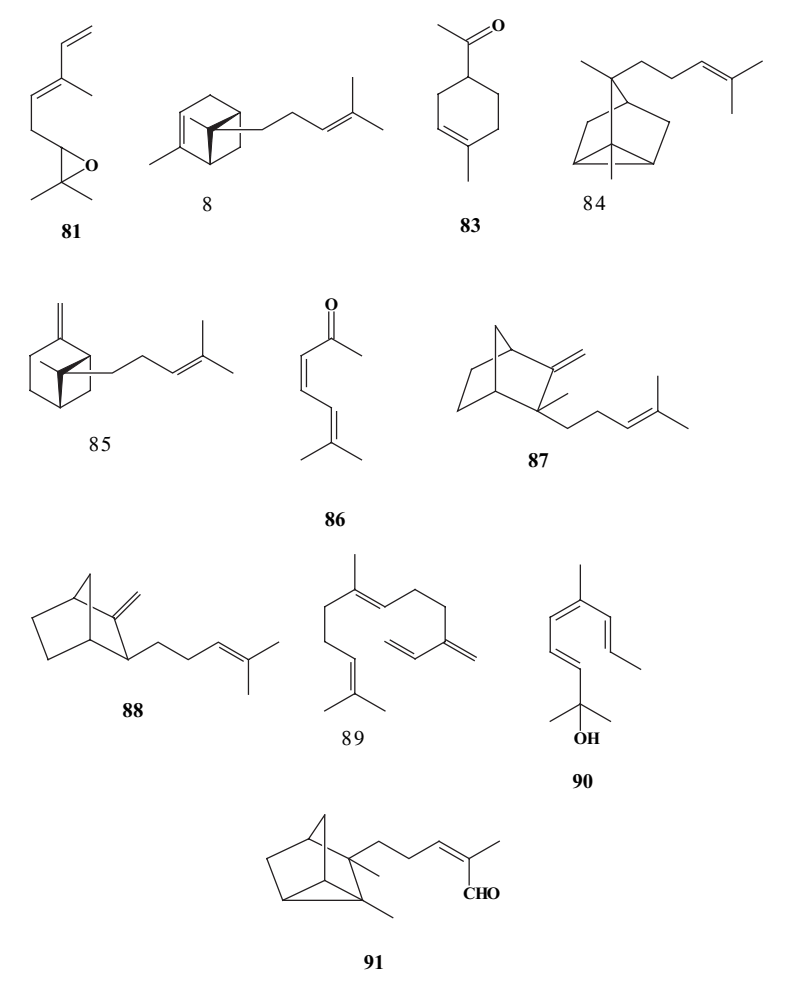

Ethyl acetate extract of an exudate of Commiphora myrrha, which had been collected in People's Republic of China, was separated by column chromatography on silica gel and RP-18 (ref. ${ }^{46}$ ). From collected fractions seven compounds (aromatic sesquiterpenes) were isolated and identified - myrrhone 92 (a weak floral with relatively strong animal-like note; a new sesquiterpene), epicurzerenone $\mathbf{4 8}$ (with the same odour as the previous one), furanogermacra-1E,10(15)-dien-6-one 93, 2-methoxy-furanogermacra-1(10),4-diene 25 (a slightly floral and weak leathery odour), T-cadinol 69 (very interesting animal and castoreum-like odour quality), $3 \alpha$-hydroxy-Tcadinol 219 (a slightly leathery odour), and a well-known sesquiterpene, eudesm-4(15)-ene-1 $\beta, 6 \alpha$-diol 222 (the same odour quality as T-cadinol).

The structures of these compounds were determined on the basis of spectral data, especially of NMR evidence $\left({ }^{1} \mathrm{H}\right.$ - and ${ }^{13} \mathrm{C}$-NMR spectra) and with the help of positive atmospheric pressure chemical ionization mass spectra (APCI MS) and electrospray ionization mass spectra (ESI MS). 


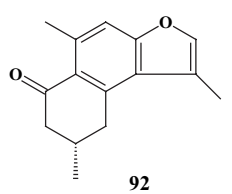

92

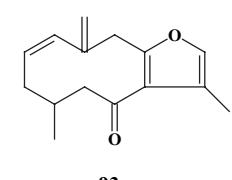

93

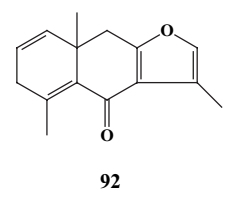

92

\section{Commiphora molmol}

From the hexane extract of the essential oil of myrrh, Commiphora molmol Engler, three new furanogermacrenes (2-methoxy-4,5-dihydrofuranodiene-6-one $22-\mathrm{C}_{16} \mathrm{H}_{22} \mathrm{O}_{3}$, 5-acetoxy-2-methoxy-4,5-dihydrofuranodiene-6-one 34 - $\mathrm{C}_{18} \mathrm{H}_{24} \mathrm{O}_{5}$ and 3-methoxy-10-methylene-furanogermacra-1-ene-6-one $49-\mathrm{C}_{16} \mathrm{H}_{20} \mathrm{O}_{3}$ ) have been with the help of column chromatography isolated and their structures elucidated ${ }^{47}$.

The non-polar fraction of hexane extract of myrrh, the resin of Commiphora molmol Engler, gave on column chromatography as the main compound the new furanoeudesmane, furanoeudesma-1,3-diene 14. Another isolated compounds were $\alpha$-copaene 53, bourbonene 44, furanodiene 36, $\beta$-elemene 39 and furanoeudesmane lindestrene 16. From the polar fraction of the essential oil another new furanosesquiterpene of the eudesmane type was isolated by liquid chromatography, furanoeudesma1,4-diene-6-one 94, besides curzerenone 17 and furanodiene-6-one 18 (ref. ${ }^{48}$ ).

From the fractionated essential oil of myrrh, Commiphora molmol, several compounds were isolated and identified by column chromatography. In addition to 1(10)E,4E-furanodiene-6-one $\mathbf{1 8}$ and its cis-isomer 1(10)Z,4Z-furanodiene-6-one 18, which were separated without difficulty, was isolated curzerenone 17 and 2-methoxyfuranoguaia-9-ene-8-one 95. 2-Methoxyfuranodiene 25 was separated from the accompanying furanoeudesma1,4-diene-6-one 94. From an accompanying unidentified furanosesquiterpene ketone was separated 2-acetoxyfuranodiene 24. The last identified compound was 4,5-dihydrofuranodiene-6-one $37\left(\right.$ ref. $\left.^{49}\right)$.

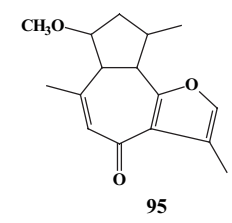

Myrrh, a commercially used resin, is mostly from Commiphora molmol, growing wild in Somalia, Jemen and Arabia. It is mainly used in toothpastes and tinctures for treatment of gingivitis. Myrrh is composed of the essential oil (2-10\%), the ethanol soluble resin (25-40\%) and the watersoluble gum (30-60\%). The watersoluble gum fraction of myrrh has been found to comprise of a mixture of proteoglycans (with dominating amounts of uronic acid polymers). After hydrolysis and degradations structural investigations revealed chains of galactose 27, chains of arabinose $\mathbf{2 8}$ and 4-O-methyl-glucuronic acid $\mathbf{2 9}$ ("4-O-methyl-glucurono-galactan"), arabino-3,6-galactanprotein fractions and protein. Authors studied sugar and amino acid compositions of the fractions and sugar linkages of the fractions. Partial structure of the fractions was proposed. The covalent binding of protein and carbohydrate moiety is most probable. In the crude gum the two aldobiuronic acids 6-O-(4-O-methyl-D-glucuronosyl)D-galactose 30 and 4-O-(4-O-methyl-D-glucuronosyl)-Dgalactose 31 were identified (ratio 6:1) $\left(\right.$ ref. $^{50}$ ). It is not sure, whether the different proteoglycans represent different polymers resulting from the biosynthesis sequence or whether they derive from a partial degradation during isolation or storage of myrrh.

In antiquity, myrrh was used by the Egyptians for embalming and by the Jews as anointing oil. In St Mark's Gospel, "vinum murratum", wine with myrrh, was offered to Christ before crucifixion. Hexane extract of Commiphora molmol with analgesic activity was separated by silica gel column chromatography and semi-preparative HPLC. From the three identified sesquiterpenes the most abundant compound was furanoeudesma-1,3-diene 14 (>90\%). The other compounds were isofuranogermacrene 13 and furanodiene $\mathbf{3 6}$. The first two compounds were analgesic ${ }^{51}$.

The non-polar fraction of myrrh resin from Commiphora molmol was extracted with hexane. This extract was separated by column chromatography. With a combination of mass spectrometry and ${ }^{1} \mathrm{H}-\mathrm{NMR}$ were characterized different fractions. These gave eight sesquiterpene fractions, namely 1 , furanodiene $\mathbf{3 6}$, furaneudesma-1,3-diene $\mathbf{1 4}$ and curzerene $13 ; 2$, methoxyfuranodiene $25 ; 3$, acetoxyfuranodiene $24 ; 4$, curzerenone 17 ; 5 , furanodiene-6-one and methoxyfuranoguaia-9-ene-8-one 95 ; 6 , furanogermacrene3 49; 7, furanogermacrene-1 22 and fraction 8, furanogermacrene-2 $34\left(\right.$ ref. $\left.^{52}\right)$. All these compounds had been described previously. The fractions were tested. Fraction 5 (furanodiene-6-one and methoxyfuranoguaia-9-ene-8-one in approximately equivalent amounts) showed antibacterial and antifungal activity against standard pathogenic strains. These compounds also had strong local anaesthetic activity.

\section{Commiphora opobalsamum}

The cardiovascular effects of aqueous extracts from the branches of Commiphora opobalsamum (syn. Commiphora gileadensis (L.) Engl.), tree from the mountains of Ramallah, were investigated. The intravenous administration of $4 \mathrm{mg} / \mathrm{kg}$ of the aqueous extract depressed systemic arterial blood pressure by $20 \%(\mathrm{P}<0.01)$ and reduced heart rate of anaesthetised rats by $14 \%(\mathrm{P}<0.05)$. The hypotensive and the bradycardiac effects were immediate and in a dose related manner. The hypotensive effect of $C$. opobalsamum was inhibited by the pretreatment with atropine sulfate (1$4 \mathrm{mg} / \mathrm{kg}$ ). These results suggest that the hypotensive effect of $C$. opobalsamum is due to the activation of muscarinic cholinergic receptors ${ }^{53}$.

\section{Opopanax}

The monoterpene hydrocarbon composition of 29 essential oils was determined with the help of downward chromatostrip procedure, followed by gas chromato- 
graphic analysis identification based on comparison of retention times with known compounds. In one of this commercially available non-citrus essential oils, opopanax (C. erythrea), were found almost entirely ocimene $\mathbf{2 6}$ with trace amounts of $\alpha$-pinene 1, sabinene 96, $\Delta^{3}$-carene 97, myrcene 52, $d$-limonene 2, and terpinolene 98 (ref. ${ }^{54}$ ).

From authentic essential oil of opoponax with the help of column chromatography followed by gas chromatography $\alpha$-bisabolene $99, \beta$-bisabolene 47 , and $\gamma$-bisabolene 100 were separated ${ }^{55}$.

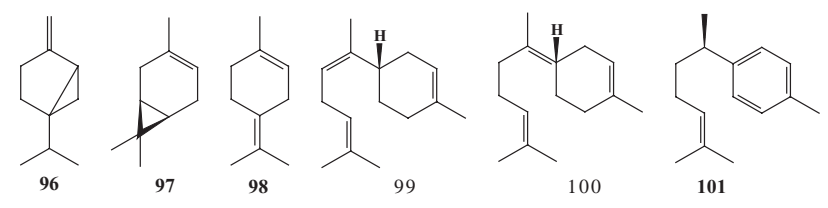

From several commercial essential oils 36 sesquiterpenes were isolated in sufficient quantity, purified by gas chromatography and identified from infrared spectra. When it was possible, the individual sesquiterpene hydrocarbon was isolated from more than one essential oil (21 sesquiterpenes). From opopanax for high resolution infrared spectra were isolated $\alpha$-bergamotene 82, $\beta$-bisabolene 47, $\gamma$-bisabolene 100 (may be a mixture), $\gamma$-cadinene 64, $\delta$-cadinene 65, ar-curcumene $(\alpha-) 101$ and $\alpha$-santalene $84\left(\right.$ ref. $\left.^{56}\right)$.

Regan and Andrews examined samples of oil of opopanax and isolated and identified in it $\alpha$-santalene 84 and $\alpha$-bisabolene 99 (ref. ${ }^{57}$ ). They did not find any $\beta$-bisabolene and $\gamma$-bisabolene.

Another scientific team re-examined their samples following column and gas chromatographic purification and concluded that oil of opopanax contains $\alpha$-santalene 84, $\alpha$-bisabolene 99 and $\beta$-bisabolene 47 , as well as some other isomeric bisabolene ${ }^{58}$.

The sesquiterpenes of opopanax oil were studied. Opopanax oil (also called bisabol myrrh) is obtained by the steam distillation of the natural oleo-gum-resin from the tree Commiphora erythrea glabrascens Engler. During this study, trans- $\beta$-ocimene $\mathbf{2 6}$ was confirmed as the major monoterpenic hydrocarbon constituent and 18 additional sesquiterpenes were identified. The five major sesquiterpene hydrocarbon constituents were identified as cis- $\alpha$-bergamotene 82, $\alpha$-santalene 84, trans- $\alpha$-bergamotene 82, trans- $\alpha$-bisabolene 99, and $\beta$-bisabolene 47. Between another 13 were $\delta$-elemene 41, $\alpha$-cubebene 43, $\alpha$-copaene 53, $\beta$-elemene 39, caryophyllene 56, $\gamma$-elemene 40 , epi- $\beta$ santalene 87, $\beta$-santalene 88, humulene 57, $\gamma$-muurolene 59, ar-curcumene 101, $\gamma$-cadinene 64, and $\delta$-cadinene 65 (ref. $\left.{ }^{59}\right)$.

For revision of the configuration of natural (+)- $\alpha$-bisabolene from opopanax oil were stereospecifically syntetised (E)- and (Z)- $\alpha$-bisabolenes. Whilst (Z)- $\alpha$-bisabolene remotely recalls the typical odour of Opopanax, there is no trace of it in (E)-bisabolene. Authors also isolated $\alpha$ bisabolene from the oil of opopanax. After purification it was identical with $(+)-(\mathrm{S}, \mathrm{Z})-\alpha$-bisabolene 99 (ref. $\left.{ }^{60}\right)$.

\section{Commiphora mukul}

The gum-resin of Commiphora mukul furnishes essential oil $(\sim 0.4 \%)$ consisting chiefly of myrcene 52 and "dimyrcene" (camphorene 102) were isolated ${ }^{61}$.

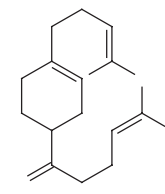

102

Composition of the gum resin from Commiphora mukul (syn. Balsamodendron mukul Hook ex Stocks), commonly known as "guggul", was studied. Complete hydrolysis of the gum revealed the presence of L-arabinose 28, D-galactose 27, L-fucose 103, 4-O-methyl-D-glucuronic acid 29 and aldobiouronic acid (built up of D-galactose and 4-O-methyl-D-glucose) 104 ( ref. $^{62}$ ).

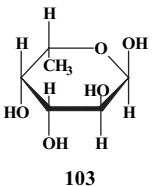

103

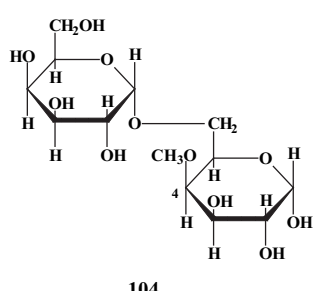

104
The degraded gum of Commiphora mukul gave after acid hydrolysis an aldobiouronic acid, 6-O-(4-O-methyl$\beta$-D-glucopyranosyluronic acid)-D-galactose alone with D-galactose. The degraded gum prepared by the autohydrolysis was converted into its fully methylated derivative. Methanolysis and subsequent acid hydrolysis of the methylated polysaccharide furnished neutral and acidic sugar fraction. Paper chromatographic separation of the neutral fraction furnished three sugars, namely 2,4,6-triO-methyl-D-galactose 105, 2,3,4-tri-O-methyl-D-galactose 106 and 2,4-di-O-methyl-D-galactose 107 and an acidic sugar fraction gave 2,3,4-tri-O-methyl-D-glucuronic acid 108 (in the ratio $1: 6: 2: 3$ ). It was established that the degraded gum is a branched polysaccharide ${ }^{63}$.

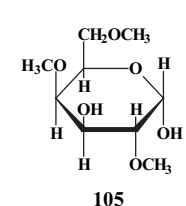

105

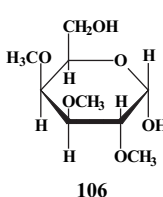

106

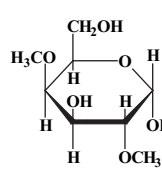

107

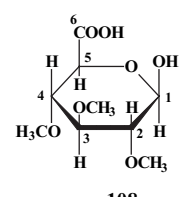

108
Hydrolysis of methylated Commiphora mukul gum furnished 2,3,4,6-tetra-O-methyl-D-galactose 109, 2,3-diO-methyl-L-arabinose 110, 2,3,4-tri-O-methyl-D-galactose 106, 2,4-di-O-methyl-D-galactose 107 and 2,3,4-tri-O-methyl-D-glucuronic acid $\mathbf{1 0 8}$ in the ratio $1: 1: 1: 2: 1$. The provisional structure advanced shows the gum to be a highly branched polysaccharide ${ }^{64}$. 

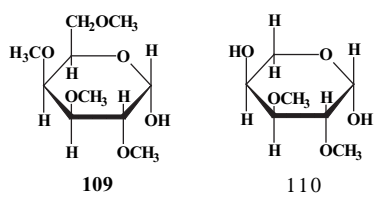

The Commiphora mukul was extracted with alcohol and the extract, after removal of the solvent, was partitioned between water and ether. Two crystalline compounds were isolated from the unsaponifiable portion of the ether-soluble residue and identified as myricyl alcohol 111 (m.p. 83-4 ${ }^{\circ}$ ) and $\beta$-sitosterol 112 (m.p. 137 $\left.8^{\circ}\right)\left(\right.$ ref. $\left.^{65}\right)$. The aqueous fraction was chromatographed by a 2-dimensional method using buthanol-acetic acidwater (100:22:50) as the solvent mixture and ninhydrin as the developing agent. The amino acids cystine, histidine, lysine, arginine, aspartic acid, serine, glutamic acid, threonine, alanine, proline, thyrosine, tryptophan, valine, leucine, and isoleucine were detected.

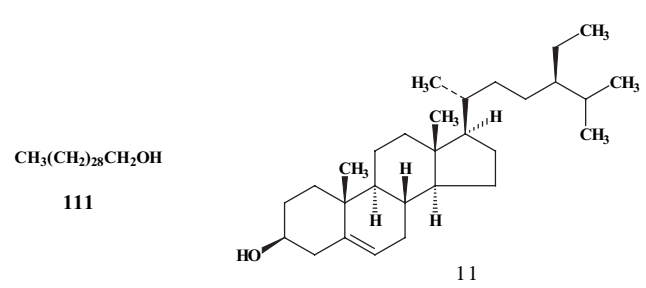

With the help of column chromatography of petroleum ether extract of Commiphora mukul a crystalline needles were isolated ${ }^{66}$. An isolated compound (steroid) showed significant anti-inflammatory activity on rat paw edema produced by carrageenin. The activity is dose dependent and much more potent than the resin fraction present in C. mukul.

The compound was found to be three times more potent than the resin fraction isolated from the same drug in inhibiting carrageenin oedema in rats. In the present study was tested efficacy of this compound in a chronic model of inflamation in rats. It looks that this drug is likely to be therapeutically effective as anti-inflammatory or anti-rheumatic drug ${ }^{67}$.

Myrcene 52, the monocyclic diterpenoids $\alpha$-camphorene 102 and cembrene 113 were isolated from gum resin of Commiphora mukul Engl (Indian gum gugul). For the diterpene alcohol allylcembrol 114, isolated from the overground parts of C. mukul, the structure 2-hydroxy4,8,12-trimethyl-1-isopropyl-3,7,11-cyclodecatriene was proposed $^{68}$.

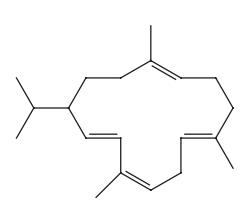

113

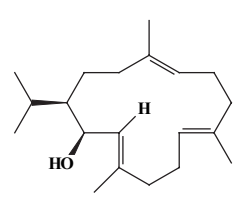

114
Mukulol (allylcembrol) 114 is a new cembrane alcohol which was isolated from the aerial parts and also from the resin of Commiphora mukul ${ }^{69}$. The allylcembrol structure was established by mild dehydration which yielded cembrene and by spectral analysis. Allylcembrol and its $\mathrm{C} 2$ epimer were synthetized from isocembrol.

Guggulu (Sanskrit) is the gum resin exudates from the tree Commiphora mukul (Hook, ex Stocks) Engl. and is article of commerce in India. Chromatography of petroleum ether soluble fraction gave a diterpene hydrocarbon $\left(\mathrm{C}_{20} \mathrm{H}_{32}\right)$, a diterpene alcohol $\left(\mathrm{C}_{20} \mathrm{H}_{34} \mathrm{O}\right),(+)$-sesamin 115, cholesterol 116 and two other new isomeric $\mathrm{C}_{21} \mathrm{H}_{28} \mathrm{O}_{2}$ steroids, which were identified as 4,17(20)-(trans)-pregnadiene-3,16-dione 117 (guggulsterone, Z-isomer) and 4,17(20)-(cis)-pregnadiene-3,16-dione 118 (guggulsterone, E-isomer). These two steroids were assigned trivial names, Z- and E-guggulsterone respectively. Ethyl acetate fraction gave additional three new sterols and a long-chain aliphatic triols. The three new sterols have been designated guggulsterol-I 119, guggulsterol-II 120 and guggulsterol-III 121 (ref. $\left.{ }^{70}\right)$.
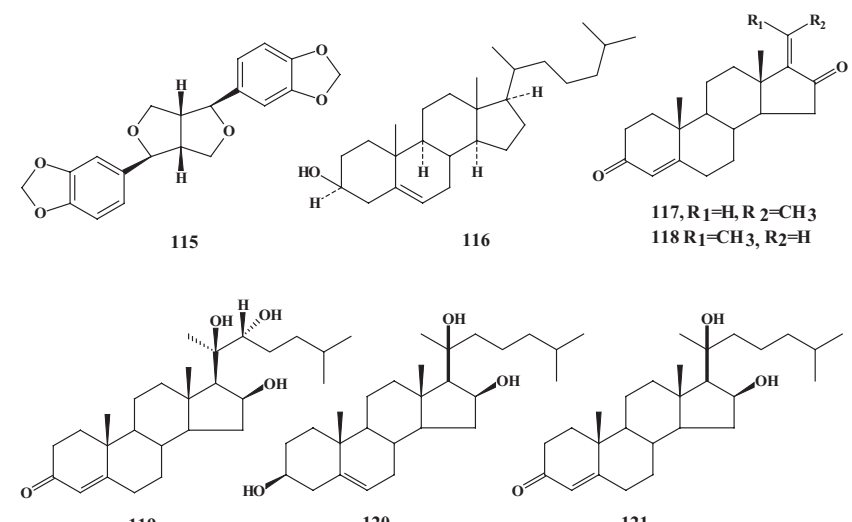

119

120

121

The structures of previously isolated new diterpene hydrocarbon and diterpene alcohol from Commiphora mukul were elucidated and named cembrene-A 122 and mukulol 114 ( ref. $\left.^{71}\right)$.

As the authors reported before, they isolated from ethyl acetate extract of the gum-resin exudates from the tree Commiphora mukul more polar fraction, which yielded colourless prismatic needles of a mixture, now identified as octadecan-1,2,3,4-tetrol 123, nonadecan-1,2,3,4-tetrol $\mathbf{1 2 4}$ and eicosan-1,2,3,4-tetrol $\mathbf{1 2 5}$ with minor amounts of other components, possibly lower $\left(\mathrm{C}_{16}, \mathrm{C}_{17}\right)$ and higher $\left(\mathrm{C}_{21}, \mathrm{C}_{22}\right)$ homologous tetrols ${ }^{72}$. This was the first reported occurrence of such compounds in nature.<smiles>C=C(C)C(CC=C(C)CCCC(C)=CCCC(C)C)CCC</smiles><smiles>CCC(C)C(O)C(O)C(C)O</smiles>

Guggulsterol IV 126 and guggulsterol V 127 were isolated from the neutral fraction after saponification of the chloroform extract of guggul gum (Commiphora mukul), and their structures were detected by NMR, mass spectra, and chemical modification ${ }^{73}$. 


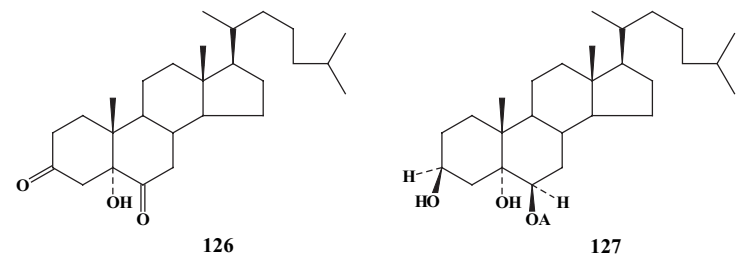

Previously described mukulol 114, a diterpenoid from gum-resin of Commiphora mukul, was studied and its absolute stereochemistry established ${ }^{74}$.

The stereochemistry of guggulsterol-I, a component of the exudate of Commiphora mukul, was established by a single crystal x-ray difraction analysis to be $20(\mathrm{R})$, 22(R) $\left(\right.$ ref. $\left.^{75}\right)$.

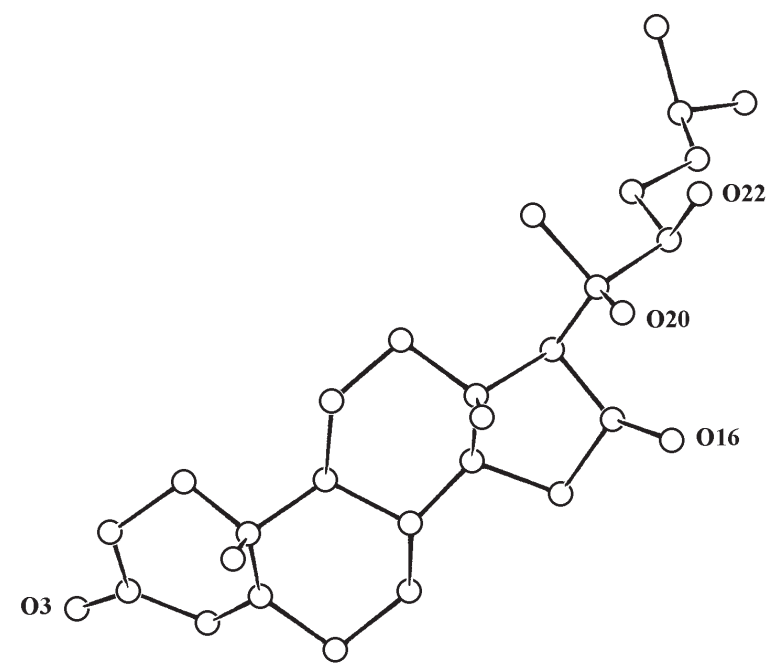

Fig. 1: A computer generated perspective drawing of guggulsterol-I. Hydrogens are omitted for clarity. Adopted by authors.

The major flavonoid components of the flowers of Commiphora mukul were identified as quercetin 128, quercetin-3-O- $\alpha$-L-arabinoside 129, quercetin-3-O- $\beta$-D-galactoside 130, quercetin-3-O- $\alpha-\mathrm{L}-$-rhamnoside 131, quercetin-3-O- $\beta$-D-glucuronide 132. The other components were ellagic acid $\mathbf{1 3 3}$ and pelargonidin-3,5-di-O-glucoside $\mathbf{1 3 4}$ $\left(\right.$ ref. $\left.^{76}\right)$.<smiles></smiles>

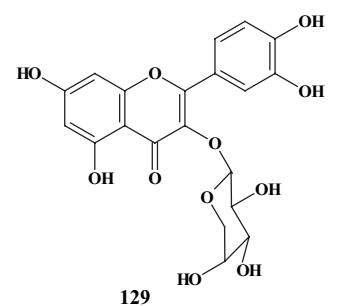

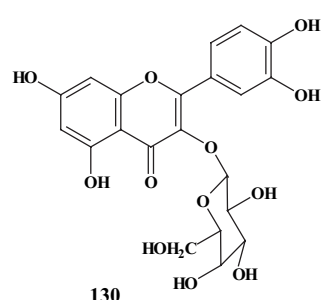<smiles>COc1ccc(-c2oc3cc(O)cc(O)c3c(=O)c2Oc2cc(O)c(O)cc2O)cc1O</smiles>

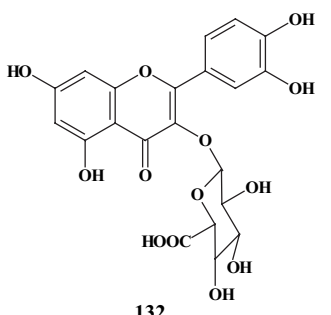

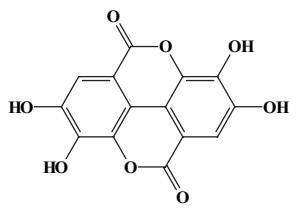

133

132
The seed oil from Commiphora mukul contained linoleic, oleic, stearic and palmitic acids. The unsaponifiable matter contained sitosterol 112, stigmasterol 135, cholesterol 116, campesterol 136, and $\alpha$-spinasterol 137 $\left(\right.$ ref. $\left.{ }^{77}\right)$.

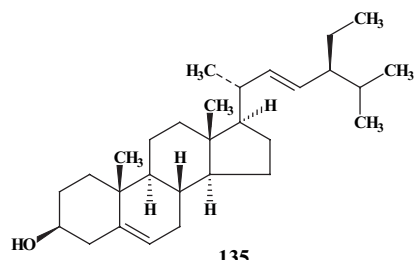

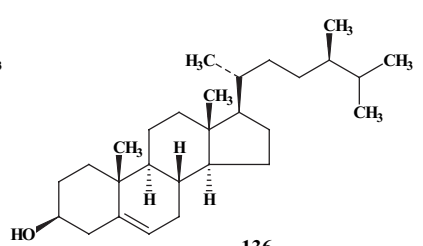

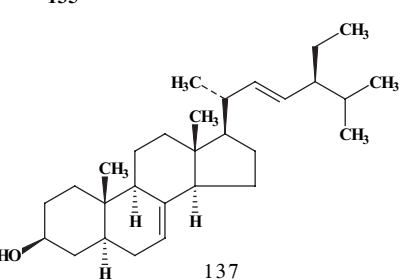

Bajaj and Sukh tried to find other minor components from the gum-resin of Commiphora mukul. The neutral ethyl acetate soluble fraction was separated on silica gel. A detailed chromatographic analysis of the less polar cut led to the isolation of four $\mathrm{C}_{21}$ steroids. Three of these, 16ß-hydroxy-4,17(20)Z-pregnadien-3-one 138 (Z-guggulsterol, this compound was reported to occur in nature for

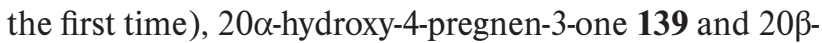
hydroxy-4-pregnen-3-one 140, were known compounds. The fourth compound, which is a new naturally occurring $\mathrm{C}_{21}$ steroid, has been designated guggulsterol-VI 141 (16$\alpha$-hydroxy-4-pregnen-3-one). Stereochemistry at C-20 and C-22 in guggulsterol-I has been clarified ${ }^{78}$. 


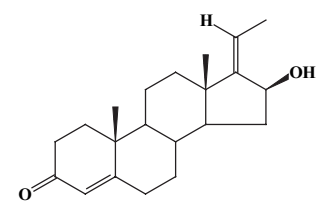

138

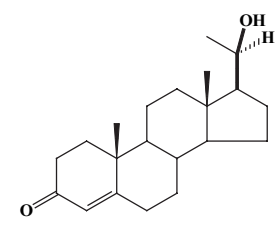

140
139

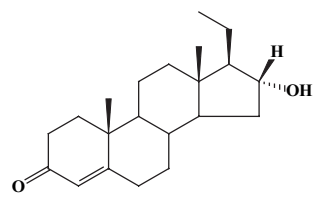

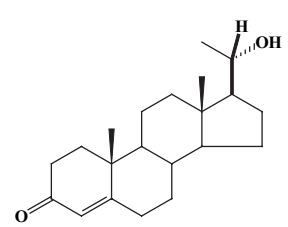

Absolute stereochemistry of a new class of naturally occurring lipids named guggultetrols, components of saponified Commiphora mukul resin, was elucidated after synthesis of these compounds. The main compound was identified by direct comparison with synthetic compounds as D-xylo (2S, 3S, 4R-configuration), e.g. D-xylo-octadecane-1,2,3,4-tetrol (D-xylo-guggultetrol-18) 142. As was already concluded earlier, guggultetrol-20 143 have the same configuration at the chiral center ${ }^{79}$.

With the discovery of the hypolipidemic activity of the gum resin, some chemical investigations have been reported. It was found that guggul resin is a complex mixture of various classes of chemical compounds, such as lignans, lipids, diterpenoids and steroids. From the benzene phase, a waxy solid, which is a mixture of esters based on homologous long chain tetrols and ferrulic acid was identified $(\mathbf{1 4 4}, \mathbf{1 4 5})\left(\right.$ ref. $\left.^{80}\right)$.
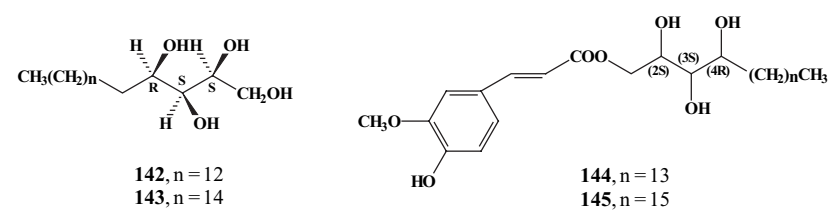

A review with 42 references on the development of gum guggulu, a potent hypolipidemic agent, in India, was published $^{81}$.

Commiphora wightii (Arnott) Bhand produces an oleo gum resin of several medicinal properties. The plant infected with Phoma sp. cause changes in the total chlorophyll (36.65\% decline), soluble sugars ( $62.77 \%$ reduced) and proteins, phenols ( $8.1 \%$ increase) and mineral elements (drastic reduction in $\mathrm{K}^{+}$and $\mathrm{Na}^{+}$) in leaf tissues ${ }^{82}$.

The resins of Commiphora mukul (source of gum guggul in India) and Commiphora incisa (a form of frankincense originating from Somalia and Ethiopia) revealed the anti-inflamatory activity. The resins were extracted by steam distillation. Isolated, previously reported, mansumbinone 146 and mansumbinoic acid 147 showed antiinflammatory effects on oedema and on adjuvant-induced $\operatorname{arthritis}^{83}$.
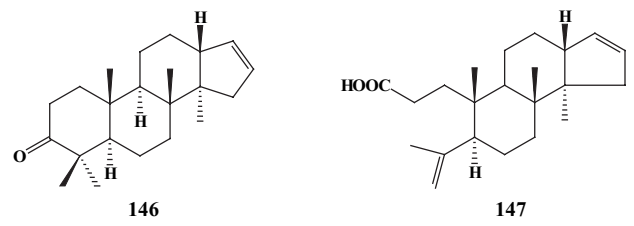

The gum resin of Commiphora mukul consisted of $\alpha$ pinene $\mathbf{1}$, myrcene 52, cadinene, geraniol 148, methylheptanone 149, eugenol 5, d- $\alpha$-phellandrene 150, d-limonene 2, ( \pm )-bornyl acetate 151, 1,8-cineole 152, ( \pm )-linalool 153, methylchavicol 154 and $\alpha$-terpineol $46\left(\right.$ ref. $\left.^{84}\right)$.
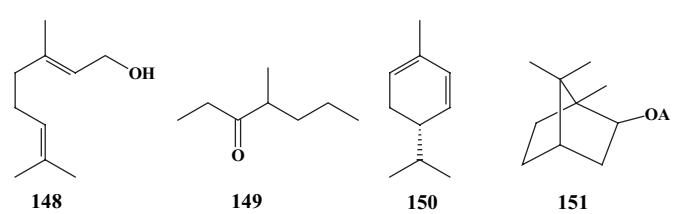<smiles>CC12CCC(O1)C(C)(C)O2</smiles><smiles>C=CC(C)(O)CCC=C(C)C</smiles><smiles>C=CCc1ccc(OC)cc1</smiles>

A high-performance liquid chromatographic method has been developed and validated for the profiling and quantitative determination of Z- and E-guggulsterones 117, 118 in Commiphora mukul (guggul) crude resin extracts and final products (tablets, capsules), used today as hypocholesterolemic ${ }^{85}$.

Z- and E-guggulsterone 117, 118 are the main ingredients of an ayurvedic drug "Guggulip", marketed in India as hypolipidaemic drug. The method was developed for simultaneous determination of these stereoisomers in spiked serum $^{86}$. Lowest quantitation limit was $25 \mathrm{ng} / \mathrm{ml}$. This method was applied for the estimation of this two stereoisomers in rat serum after a single oral dose of Zisomer. Repeated analysis showed that the $\mathrm{Z} \rightarrow \mathrm{E}$ conversion does not take place in the spiked serum samples, and hence the formation of the E-isomer can be attributed solely due to the in vivo process.

Biotransformation of E-guggulsterone (pregna4,17(20)-cis-diene-3,16-dione) 118 by Aspergillus niger resulted in the formation of four near hydroxyl derivatives identified as 7 $\beta$-hydroxypregna-4,17(20)-trans-diene-3,16dione 155, 7 $\beta$-hydroxypregna-4,17(20)-cis-diene-3,16-dione 156, 7 $\beta$-hydroxypregn-4-ene-3,16-dione 157, and $7 \beta, 15 \beta$ dihydroxypregn-4-ene-3,16-dione 158. The biotransformation of 1 with Cephalosporium aphidicola also resulted in the formation of four new steroidal derivatives as $11 \alpha$-hydroxypregna-4,17(20)-trans-diene-3,16-dione 159, $11 \alpha$-hydroxypregna-4,17(20)-cis-diene-3,16-dione $\mathbf{1 6 0}$, $11 \alpha, 15 \beta$-dihydroxypregna-4,17(20)-trans-diene-3,16-dione 161, and $11 \alpha, 15 \beta$-dihydroxypregna-4,17(20)-cis-diene-3,16dione 162. The structures of these compounds were elucidated on the basis of $1 \mathrm{D}$ and 2D NMR spectroscopic techniques $^{87}$. 


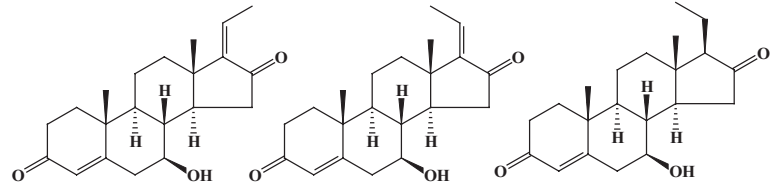

155

156

157

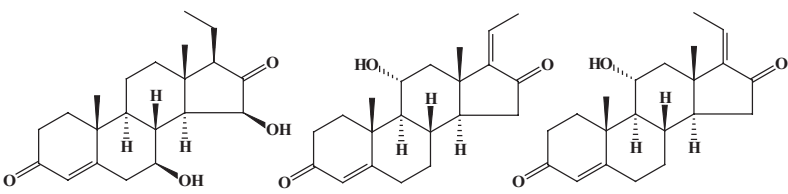

160

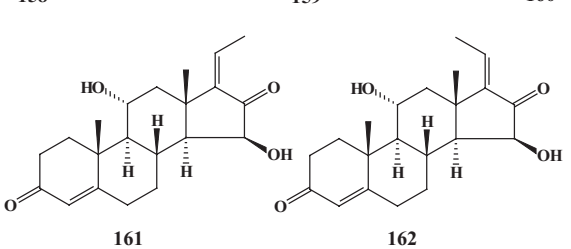

The gum resins of guggul (Balsamodendron or Commiphora mukul Hook.) are prescribed in India as Ayurvedic folk medicines. Guggul is produced by drying the milky-white sap of the tree for one year. From methanolic extract were isolated five new polypodane-type triterpene compounds, myrrhanols $\mathrm{A}, \mathrm{B}$, and $\mathrm{C}$, and myrrhanones $\mathrm{A}$ and $\mathrm{B}$, together with three known constituents. Myrrhanol A 163 and myrrhanone A 165 were characterized. Myrrhanol A displays a potent anti-inflammatory effect ${ }^{88}$. The structures and absolute configurations of myrrhanol A and myrrhanone A were determined on the basis of chemical and physicochemical evidence ${ }^{89}$.

From the methanolic extract from guggul-gum resin, the resin of Commiphora (Balsamodendron) mukul, three new polypodane-type triterpenes, myrrhanol B 167 and myrrhanones B 168 and A acetate 170, and a new octanordammarane-type triterpene, epimansumbinol 171, were isolated together with 17 known compounds - myrrhanol A, myrrhanone A, (8R)-33,8-dihydroxy-polypoda-13E,17E,21triene (myrrhanol C) 169, (8R)-3-oxo-8-hydroxy-polypoda-13E,17E, 21-triene 166, 4-pregnene-3,16-dione, 20S-acetyloxy-4-pregnene-3,16-dione, 4,17(20)-(cis)-pregnadiene-3,16-dione, 4,17(20)-(trans)-pregnediene-3,16-dione, $16 \beta$-acetyloxy-pregn-4,17(20)-trans-dien-3-one, $3 \alpha$-acetyloxy-5 $\alpha$-pregnan-16-one, 20R,22R-dihydroxycholest-4-en-3one, guggulsterol-I, isocembrol 172, 4-epiisocembrol 173, mukulol, and diayangambin $\mathbf{1 7 4}$. The $50 \%$ aqueous methanolic extract showed potent anti-inflammatory effect on adjuvant-induced air-pouch granuloma in mice ${ }^{90}$.

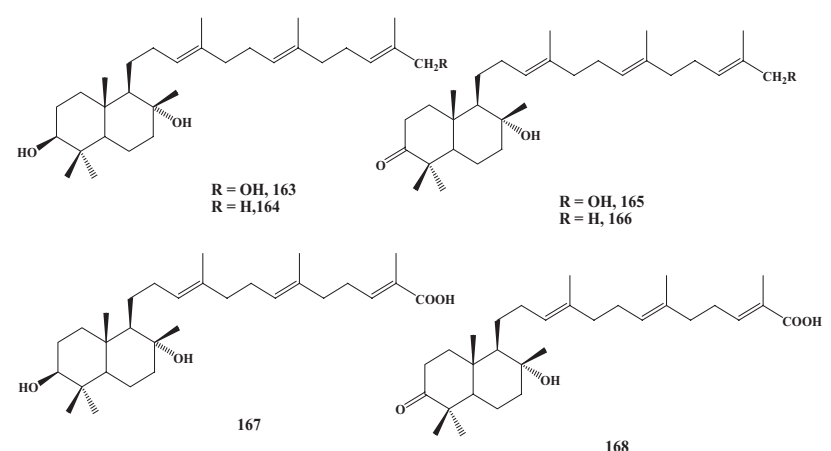

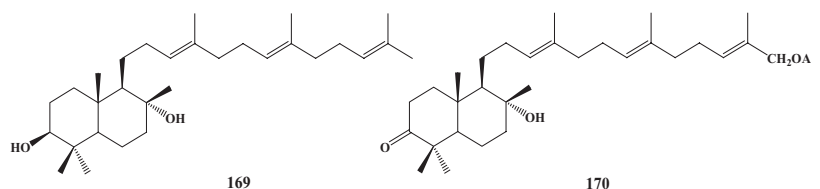

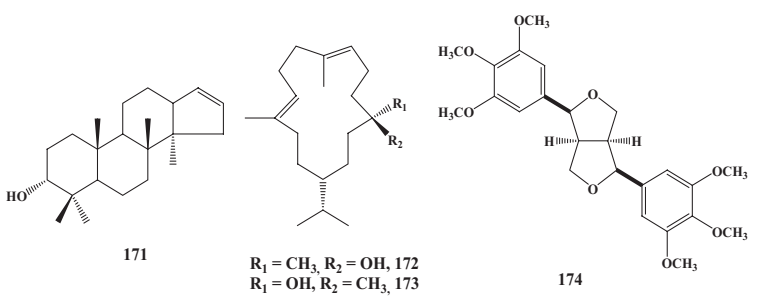

The conformation of steroid nucleus of guggulsterone E 118, isolated from ethyl acetate extract of Commiphora mukul, was studied ${ }^{91}$. The study did not establish the absolute configuration of this molecule. It has been marked in India as hypolipidaemic drug.

Commiphora wightii is a branched shrub or a small tree found in some states of India and Pakistan. Guggul, the exudates of $C$. wightii is used in Ayurvedic literature as medicine. Guggul lipid (= a mixture of lipid steroids isolated from the resin) is a potent hypolipidemic agent. It was found that the ethyl acetate extract of $C$. wightii showed significant in vitro cytotoxicity. After column chromatography two ferrulates were characterized. The absolute configuration of one of the known ferulates (guggultetrol-18 142), was deduced as D-xylo $(2 \mathrm{~S}, 3 \mathrm{~S}$, 4R-configuration). The alcohols obtained by hydrolysis of the ferulates were concluded to be a mixture of (Z)-5tricosene-1,2,3,4-tetraol 175 and (Z)-5-tetracosene-1,2,3,4tetraol $176\left(\right.$ ref. $\left.{ }^{92}\right)$. This new class of naturally occurring lipids showed strong cytotoxic activity and some free radical scavenging activity.<smiles>CCCCC(C)C(C)C(C)CCCCC1=C[C@@H](C)[C@H](C)C1</smiles>

Three new and five known compounds were isolated from the oleogum resin of Commiphora wightii (Arnott.) Bhand. [syn. = Commiphora mukul (Hook ex Stocks) Engl.], which is endemic to the Indian peninsula and grows wild in India and Pakistan. This exudates possess a variety of pharmacological activities. Five previously isolated compounds were Z-guggulsterone 117, E-guggulsterone 118, guggulsterol-I 119, myrrhanol A 163 and myrrhanone A 165. Another three compounds, Guggulsterone-M 177, dehydroguggulsterone-M 178 and guggulsterol-Y 179, were new ${ }^{93}$. 


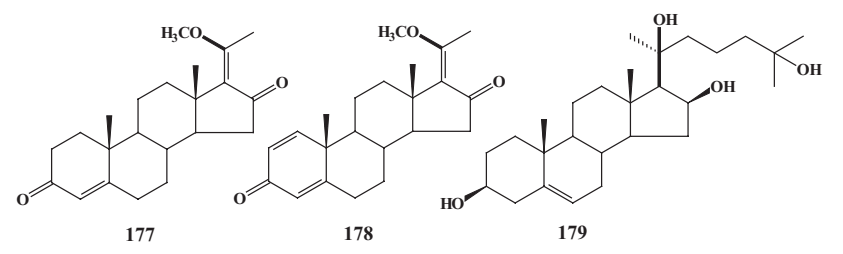

An ethanolic extract of air-dried trunk of Commiphora wightii (Arn.) Bhandari (=C. mukul Hoox ex Stocks) was separated on column packed with silica gel to give a new antifungal flavone named muscanone $\mathbf{1 8 0}$ and already known naringenin $181\left(\right.$ ref. $\left.{ }^{94}\right)$. Muscanone was active agains Candida albicans in microbial sensitive assay.<smiles>CCC(C)=CCCCCCC(C)CCCCCCC(C)OC1C(=O)c2c(O)cc(O)cc2OC1c1ccc(O)cc1</smiles>

Guggulu, the gum resin from Commiphora mukul, was boiled with water prior to extractions. Bioassayguided isolation of compounds from the hexane-soluble portion of the methanol extract of guggulu yielded 14 compounds. Seven of them, (1E,4E,8E)-4,8,14-trimethyl11-(1-methylethyl)-14-methoxycyclotetradeca-1,4,8-triene 182, (2E,12E)-2,7,13-trimethyl-9-(1-methylethyl)-15oxabicyclo[12.1.0] pentadeca-2,12-dien-7-ol 183, (4Z,6E)-4,7,12,15,15-pentamethylbicyclo[9.3.1]pent adeca-4,6-dien-12-ol 184, pregn-4-ene-3,16-dione 185, (13E,17E,21E)-8-hydroxypolypodo-13,17,21-trien-3-one 186, (13E,17E,21E)-polypodo-13,17,21-triene-3,18-diol 187 and 5,5'-tetrahydro-1H,3H-furo[3,4-c]furan-1,4-diylbis[7-(methoxy)-1,3-benzodioxole] 188 were novel compounds ${ }^{95}$.

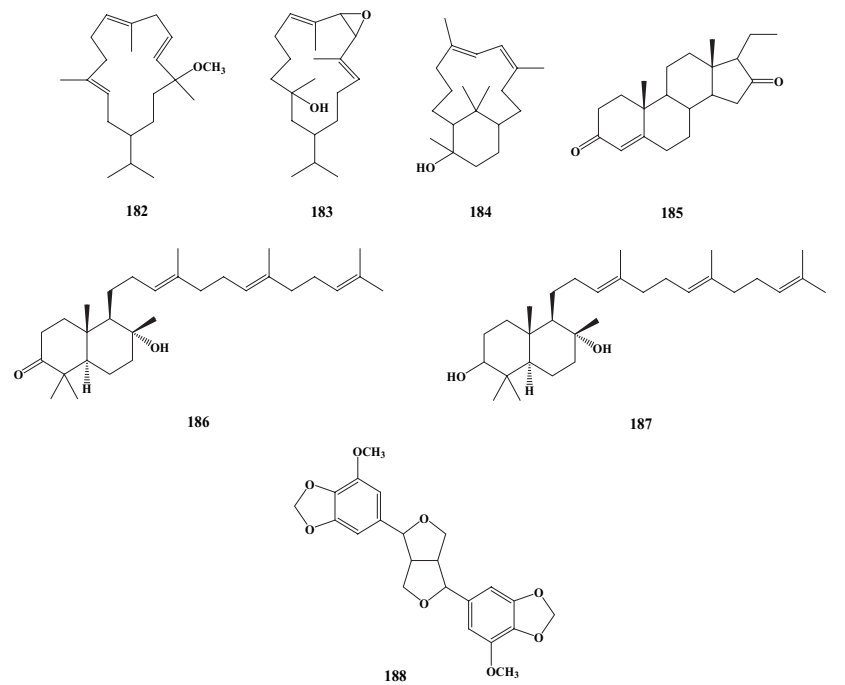

\section{Other Commiphoras}

During the initial study were found in petrol extract of the stem bark of Commiphora kua three labile $\mathrm{C}_{22}$ octanordammarane triterpenes, 16-hydroperoxymansumbin-13(17)en-3-one 189, 16-hydroperoxymansumbin-13(17)-en-3 $\beta$-ol 190 and 16-hydroperoxy-3,4-seco-mansumbin-3(28),13(17)dien-3-oic acid 191 which rapidly degraded to give breakdown products identified as mansumbin-13(17)-en3,16-dione 192, 33-hydroxymansumbin-13(17)-en-16-one 193 and 16-oxo-mansumbin-3(28),13(17)-dien-3-oic acid 194 (ref. ${ }^{96}$ ).

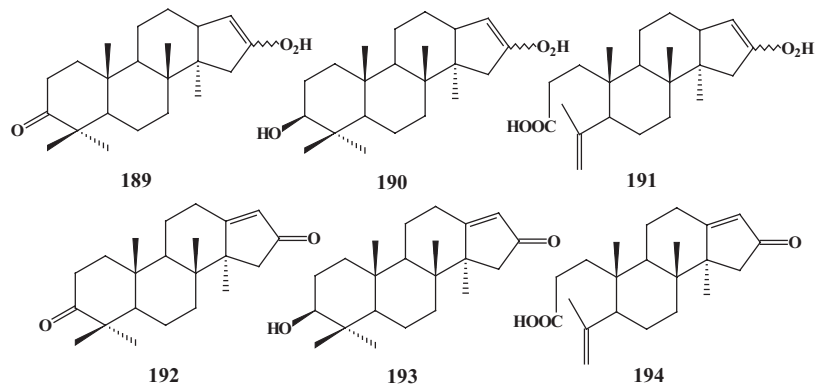

Steam distillation of the oleo-resin of Commiphora kua var. kua Vollesen (syn. Commiphora flaviflora), a tree growing wild in Kenya, Ethiopia and Somalia, gave a volatile oil, in which was found $\alpha$-pinene 1, p-cymene 45, $\alpha$-thujene 195, $\beta$-pinene 196, limonene 2 , sabinene 96, terpinene-4-ol 197, car-3-ene 97 and myrcene 52. In the residue after steam distillation and after ethyl acetate extraction and column chromatography were identified these known furanosesquiterpenoids, 2-O-acetyl-8,12epoxygermacra-1(10),4,7,11-tetraene 24 and 2-O-methyl8,12-epoxygermacra-1(10),4,7,11-tetraene 25, a known bisabolene, xanthorrhizol 198, and a new bisabolene, 2methyl-5-(5'-hydroxy-1',5'-dimethyl-3'-hexenyl)phenol 199 (ref. $\left.{ }^{97}\right)$.

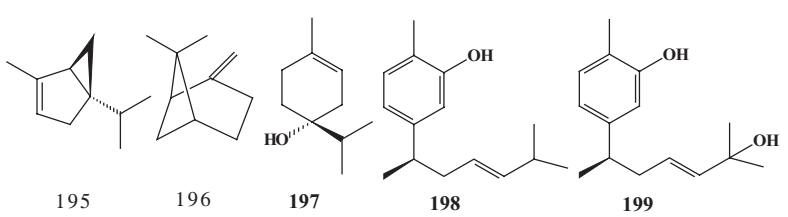

Four active compounds, mansumbinone 146, mansumbinoic acid 147, picropolygamain 200 and lignan-1 (methoxy-1,2,3,4-tetrahydropolygamain) have been purified from anti-inflammatory extracts of Commiphora kua ${ }^{98}$. These molecules inhibit the formation of myeloperoxidase products.

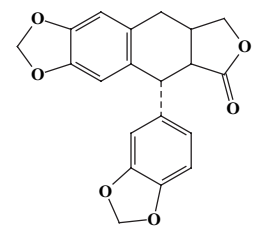

200 
Commiphora kua (J. F. Royle) Voleesen var. gowlello (Sprague) J. B. Gillett, a 3-5 m tall tree is found mainly in Kenya, Somalia, Ethiopia and Arabia. It produces wood that is used to make household utensils, furniture and tools. During rainy season, its trunk is cut and sucked to quench thirst. In dry season, the tree produces a brown resin, which is used as incense.

Ground resin from this tree was extracted with petrol. TLC analysis of this extract indicated the presence of at least six compounds. With the help of column chromatography over silica gel four already known compound - mansumbinone 146, mansumbinol 201, (16S, 20R)-dihydroxydammar-24-en-3-one 202 and T-cadinol 70 - and two new octanordammarane triterpenes, $15 \alpha$-hydroxymansumbinone 203 and 28-acetoxy-15 $\alpha$-hydroxymansumbinone 204, were isolated and identified. Structures of these two compounds were elucidated by spectroscopic techniques (MS, IR, UV, ${ }^{1} \mathrm{H}$ - and ${ }^{13} \mathrm{C}$-NMR, X-ray analysis $)^{99}$.

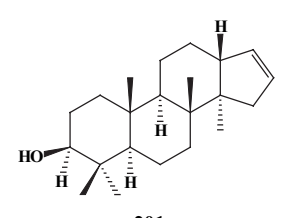

201

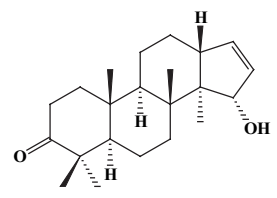

203

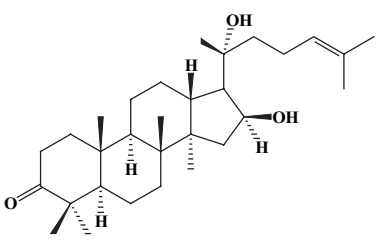

202

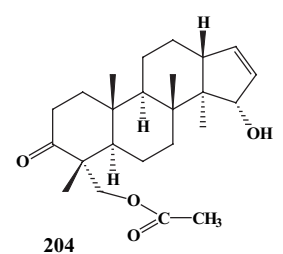

204
The residue from steam distilled resin of Commiphora $k u a$, collected near Wajir in Kenya, a novel bisabolene, 6-hydroxy-2-methyl-5-(5'-hydroxy-1'(R),5'-dimethylhex3'-enyl)-phenol 205 together with two new dammarane triterpenes, $3 \beta, 16 \beta, 20(\mathrm{~S}), 25$-tetrahydroxydammar-23-ene

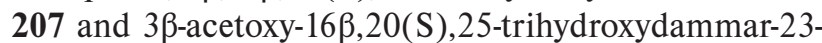
ene 208, have been isolated after extraction with ethyl acetate and column chromatography on silica gel. In addition were identified known compounds as 2-methyl5-(4'(S)-hydroxy 1'(R),5'-dimethylhex-5'-enyl)-phenol

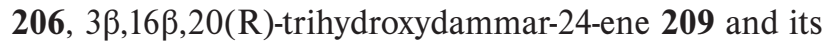
acetate derivative, $3 \beta$-acetoxy-16 $\beta, 20(\mathrm{R})$-dihydroxydammar-24-ene 210, $\beta$-amyrin 211 and its acetate derivative, 2-methoxyfuranodienone, and 2-acetoxyfuranodienone. 2Methyl-5-(4'(S)-hydroxy-1'(R),5'-dimethylhex-5'-enyl)-phenol 206 displayed fungicidal activity against Cladosporium cucumernum on TLC assay ${ }^{100}$.

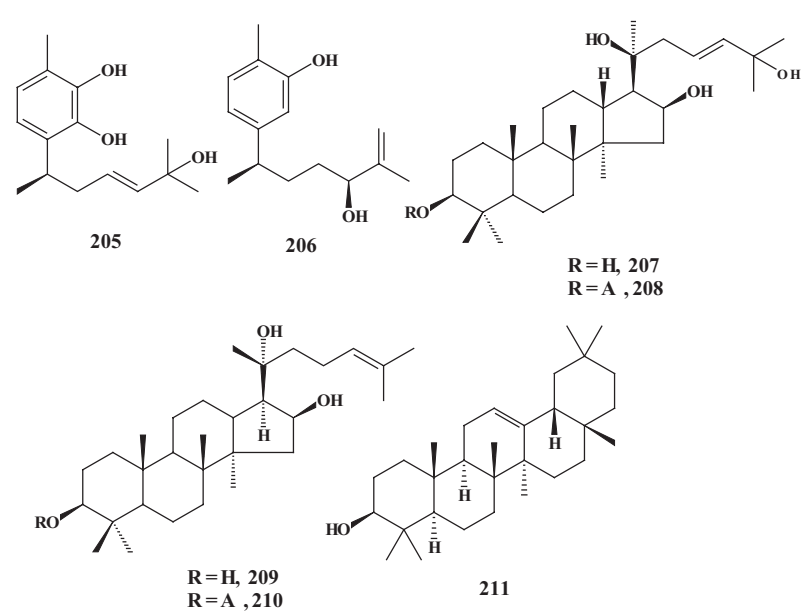

The genus Commiphora Jacq. (= Balsamodendron Kunth), natural order Burseraceae, has not been extensively studied before. Myrrh is usually obtained from C. abyssinica (Berg) Eng1., C. molmol Engl. and $C$. opobalsamum (L.). It has been found to consist of volatile oils, mostly mono- and sesquiterpenes. The presence of triterpenes has never been suggested.

C. pyracanthoides Engl. (= C. glandulosa Schinz), a tree growing in the arid parts of Southern Africa, is rich source of triterpene acids, both free and combined as glycosides. Five free acids (comic acid A 212, B 213, C 214, D 215, and E 216) were isolated from the ethereal solution of the resin ${ }^{101}$. In contrast, the resin from $C$. mukul is completey devoid of triterpenoids.

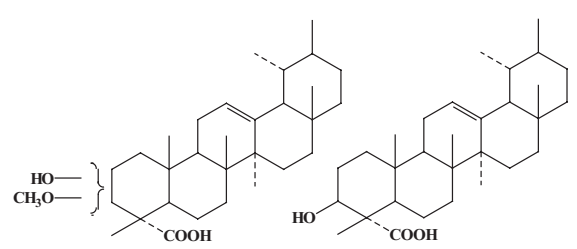

$212 \quad 213$

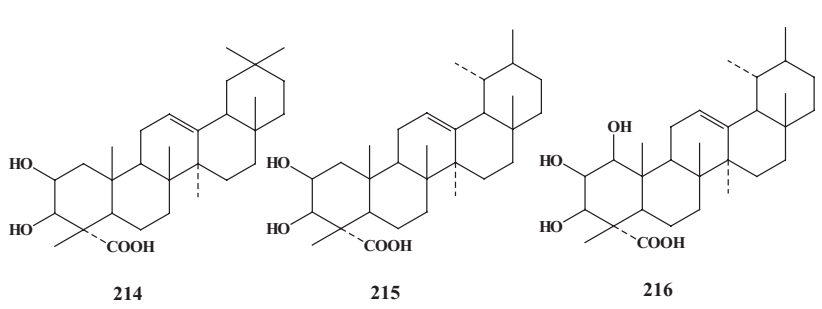

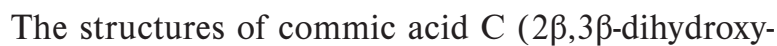
olean-12-ene-23-oic acid) 214 and commic acid D

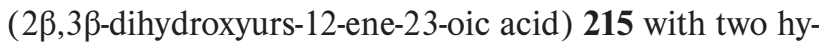
droxyl groups and one double bond from Commiphora pyracanthoides Engl. were elucidated ${ }^{102}$.

Another communication concerns the structure of comic acid E 216 (1 $1 \beta, 2 \beta, 3 \beta$-trihydroxyurs-12-ene-23oic acid) with three hydroxyl groups from Commiphora pyracanthoides Engl. ${ }^{103}$.

From the essential oil of $C$. guidotti, isolated by steam distillation of the gum resin, seven sesquiterpene hydrocarbons and one furanosesquiterpenoid, fuaranodiene, 
were identified. The GC/MS revealed car-3-ene 97, $\alpha-84$ and $\beta$-santalene $\mathbf{8 8}$, epi- $\beta$-santalene $\mathbf{8 7}$, $\beta$-bergamotene $\mathbf{8 5}$, $\beta$-farnesene 89, $\alpha-99$ and $\beta$-bisabolene 47, and furanodiene 36 (ref. ${ }^{104}$ ). The structures of three main compounds - $\alpha$-santalene, $\alpha$-bisabolene and furanodiene - were confirmed, after their isolation with the help of HPLC in pure form, by MS, ${ }^{1} \mathrm{H}-\mathrm{NMR}$ and ${ }^{13} \mathrm{C}$-NMR.

An ethyl acetate extract of a resin of Commiphora guidottii Chiov. (scented myrrh, bissabol) gave after purification on column packed with silica gel the pharmacologically active (smooth muscle relaxing effect) sesquiterpene (+)-T-cadinol 69 (ref. ${ }^{105}$ ).

Ethyl acetate extract of scented myrrh (Commiphora guidotti Chiov.) was purified by silica gel chromatography and seven compounds were obtained. The major component, T-cadinol 69, has previously been shown to possess smooth muscle-relaxing properties. Between other isolated compounds, more polar sesquiterpenes, cadinanetriol

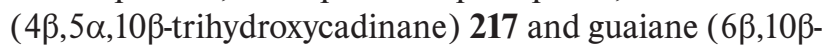
dihydroxy-4(15)-guaiene) $\mathbf{2 1 8}$ were new compounds. $3 \alpha$ Hydroxy-T-cadinol 219 and 3-oxo-T-cadinol 220 were reported for the first time as natural products. Already known isolated compounds were identified as (-)-oplopanone 221 and eudesme 222 (ref. ${ }^{106}$ ). The smooth muscle relaxing properties of all isolated compounds were 5-10 times less potent than that of T-cadinol (cadinanetriol was inactive).<smiles>CC(C)C1CCC(C)(O)C2CC[C@](C)(O)[C@H](O)[C@@H]12</smiles>

217<smiles>CC1=CC2C(C(C)C)CCC(C)(O)[C@@H]2CC1=O</smiles>

220

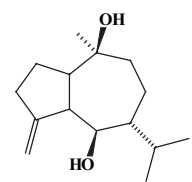

218

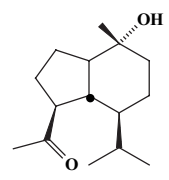

221

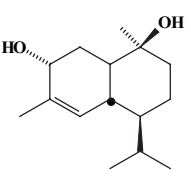

219

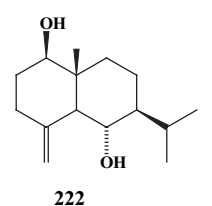

222
It is concluded that the botanical origin of scented myrrh - "bissa bol" (Hindi) or "hebbakhade" (Somali) - a major article for export from Somalia since ancient times, is Commiphora guidottii (Burseracae) and not C. erythraea as generally has been presumed. The reasons for the previous confusion were discussed and an updated synonymy and distribution map for C. guidottii was given ${ }^{107}$.

The mass spectra of previously isolated methyl commates A to E 212-216 from Commiphora pyracanthoides were illustrated ${ }^{108}$.

From hexane extract of the essential oil of Commiphora abyssinica (Berg) Engler have been with the help of column and preparative chromatography isolated $\alpha$-pinene $\mathbf{1}$, limonene $\mathbf{2}$, dipenthene, cuminaldehyde $\mathbf{3}$, cinnamaldehyde 4, eugenol 5, $m$-cresol 6, formic acid, acetic acid, palmitic acid, nine sesquiterpene hydrocarbons ( $\delta$-elemene 41, $\beta$-elemene 39, $\alpha$-copaene 53, $\beta$-bourbonene 44, germacrene D 60, caryophyllene 56, humulene 57, $\gamma$-cadinene 64 and $\delta$-cadinene 65 ), the sesquiterpene alcohol (elem- ol 42) and the furanosesquiterpenoids furanodiene $\mathbf{3 6}$, furanodienone $\mathbf{1 8}$, isofuranogermacrene $\mathbf{1 3}$, curzerenone 17 and lindestrene 16 (ref. ${ }^{109}$ ).

A Bursera latex containing 6.5\% steroid fraction (a) was obtained from Commiphora abyssinica and separated by column chromatography to give $\underline{\text { a }, ~ m . ~} 144-6^{\circ},[\alpha]_{\mathrm{D}}{ }^{20}$ $-37^{\circ}$, and a was acetylated to give a product, mp. $112^{\circ}$, $[\alpha]_{\mathrm{D}}^{20}-45^{\circ}$. The mass spectrum of a shows the presence of

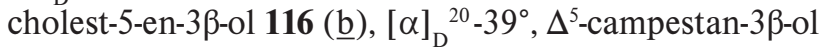

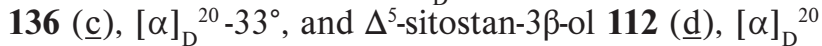
$-36^{\circ}$. NMR data for a were given. a contains $68 \% \underline{b}, 9 \%$ c, and $5 \% \underline{\mathrm{d}}\left(\right.$ ref. $\left.^{110}\right)$.

The gum of Bdellium that was studied was African in origin, produced by Commiphora africana. The Galbanum gum probably came from Ferula galbaniflua. The former gum was more resistant to hydrolysis than the latter, contained more protein, and consumed more periodate during oxidation. In both instances galactose 27 and arabinose $\mathbf{2 8}$ were resistant to oxidation, suggesting that these sugars were involved in $1 \rightarrow 3$ linkages or branching at position 3. The amount of $\mathrm{HCOOH}$ produced was higher in the case of Bdellium gum, and suggested the oxidation of terminal molecules and branching. The uronic acids were galacturonic 220 and 4-methyl-glucuronic 224, the latter predominating ${ }^{111}$.
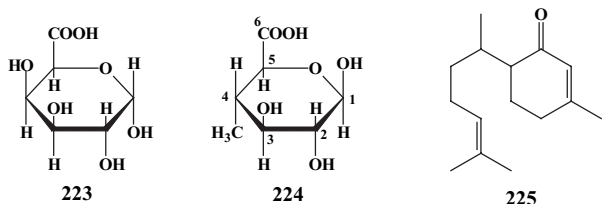

The essential oils obtained from the leaves of Commiphora africana and Xylopia aethiopica from Benin were analyzed by GC, GC/MS and ${ }^{13} \mathrm{C}-\mathrm{NMR}$. Leaf essential oil of $C$. africana contained fairly high amounts of sesquiterpenes, among which $\alpha$-oxobisabolene 225 was the most important (61.6\%). X. aethiopica was characterized by a high content of $\beta$-pinene 196 (34.9\%), elemol 42 $(14.9 \%)$ and $\alpha$-pinene $1(11.6 \%)^{112}$. The leaf essential oil of $X$. aethiopica contained mainly sesquiterpenoid compounds which amount to about $36.6 \%$.

The leaf oil of Commiphora africana, obtained by hydrodistillation, has been analyzed by GC, GC/MS coupling and ${ }^{13} \mathrm{C}-\mathrm{NMR}$ spectroscopy (Table 5). The two major compounds identified in the oil were $\alpha$-oxobisabolene $225(61.6 \%)$ and $\gamma$-bisabolene $100(10.0 \%)^{113}$.

The methanolic extract of bark of the plant Commiphora africana gave a homogenous product through chromatographic separation which after crystallization from methanol furnished needles characterized as dimethylterephthalene (benzene-1-dicarboxylic acid dimethylester) 229 on the basis of spectral analysis ${ }^{114}$. 
Table 5. Relative concentrations (\%) of volatile components of the leaf oil of Commiphora africana (A. Rich.) Engl. from Benin.

\begin{tabular}{|l|c|}
\hline \multicolumn{1}{|c|}{ Compound } & Percentage \\
\hline$\alpha$-thujene 195 & 0.1 \\
$\alpha$-pinene 1 & 0.2 \\
p-cymene 45 & 0.1 \\
1,8-cineole 152 & 0.1 \\
cyperene 226 & 0.4 \\
$\beta$-caryophyllene 56 & 0.4 \\
(Z)- $\beta$-farnesene 89 & 4.7 \\
aromadendrene 58 & 1.5 \\
$\alpha$-humulene 57 & 0.2 \\
ar-curcumene 101 & 3.5 \\
germacrene D 60 & 0.5 \\
$\beta$-selinene 38 & 0.4 \\
$\beta$-bisabolene 47 & 3.1 \\
(Z)- $\gamma$-bisabolene 100 & 10.0 \\
spathulenol 227 & 0.2 \\
$\alpha$-bisabolol 228 & 4.0 \\
$\alpha$-oxobisabolene 225 & 61.6 \\
ar-curcumene 101 & 3.5 \\
\hline
\end{tabular}

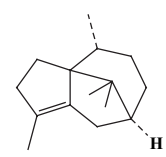

226
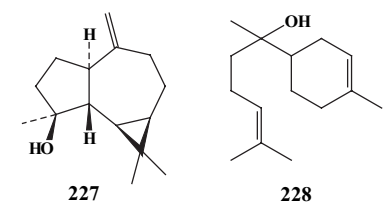

228

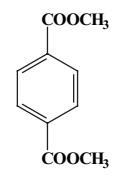

229
A heavily spined shrub or small tree found in Kenya, Commiphora incisa Chiov. (syn. C. candidula Sprague), exudes after injury a liguid, which quickly hardens and formed resin becomes with age crystalline. An ether extract of this resin was prepared. On chromatographic column packed with silica two aryltetralin lignans were isolated. The first lignan appeared to be the known lignan polygamain 230 [Hokanson G.C.: J. Nat. Prod. 42, 378 (1979)] previously reported from Polygala polygama Walt. The second one, an isomer of the first one, was identified as picropolygamain $\mathbf{2 0 0}$ (ref. $^{115}$ ).

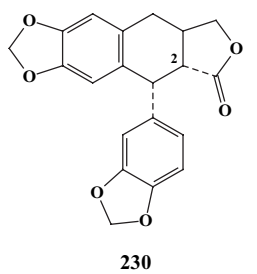

The resin of Commiphora incisa Choiv. (syn $C$. candidula Sprague) collected in Kenya and extracted with diethyl ether gave after purification on column with silica gel two already known lignans (polygamain and picropolygamain) and four triterpene deraivatives (mansumbinone
146, 3,4-seco-mansumbinoic acid 147, mansumbinol 201 and 16(S),20(R)-dihydroxydammar-24-en-3-one) 202 (ref. ${ }^{116}$ ). (It was later found to be C. kua.)

Authors referred, that about one half of the samples, previously reported as Commiphora incisa has now been identified as being of Commiphora kua (J. F. Royle) Vollesen (?syn. C. flaviflora). Diethyl ether extracts of $C$. incisa gave after chromatographic column minor compound $1 \alpha$-acetoxy-9,19-cyclolanost-24-en-3 $\beta$-ol 231 and the major compound 29-norlanost-8,24-dien- $1 \alpha, 2 \alpha, 3 \beta$ triol 232 (ref. $^{117}$ ).

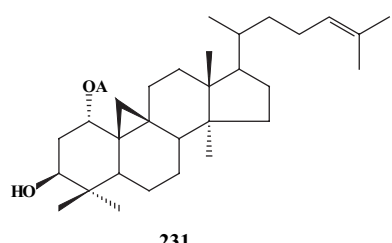

231

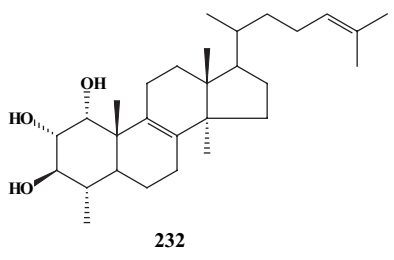

232
Commiphora rostrata grows in Kenya, Somalia and Ethiopia. It is small tree up to $3 \mathrm{~m}$ height. The simple leaves are edible. Gas chromatography revealed in the oil from stem bark volatile resin at least 30 components, the 22 have been identified as: 2-octanone, 2-nonanone, 2-decanone (65\% in resin), 2-undecanone ( $24 \%)$, 2-dodecanone (5\%), 2-tridecanone, 3-undecanone, 2-tetradecanone, 2-pentadecanone, 2-decanol, 2-undecanol, 2-dodecanol, 2,2-dimethylnonanol, 2,2-dimethyldecanol, 2,2-dimethylundecanol, 2,2-dimethyldodecanol, tridecanal, tetradecanal, pentadecanal, hexadecanal ( $1.5 \%)$, heptadecanal and octadecanal $^{118}$. It seems probable that the volatile resin of C. rostrata plays a role in defence against potential pests and pathogens.

The major alkanone constituents of the resin of Commiphora rostrata, 2-decanone and 2-undecanone, and a series of structural analogues were bioassayed for their repellency against the maize weevil, Sitophilus zeamais in olfactometric assays ${ }^{119}$. All the aliphatic ketones and aldehydes showed comparable or greater activity than the synthetic commercial insect repellent $N, N$-diethyl toluamide (DEET). In the 2-alkanone series the C-8 and C-9 compounds demonstrated significantly higher activity than their shorter- and longer-chained congeners. Analogues differing in the relative positions of the carbonyl group, including aldehydes, showed a variable pattern of repellency. Alkanols appeared to be mildly attractive to the weevil. The results supported author's previous suggestion that the resin constituents may play an allomonal role in the ecosystem where the plant thrives.

A new pentacyclic triterpene, $2 \alpha, 3 \beta, 23$-trihydroxyolean-12-ene 233, was isolated from the roots of Commiphora merkeri ${ }^{120}$. The compound has anti-inflammatory and analgesic activity. 


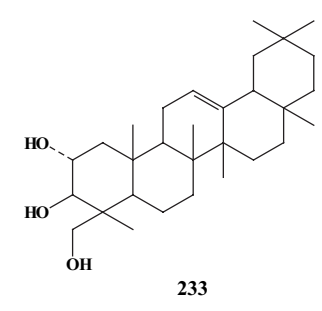

Extraction of the stem bark of Commiphora dalzielli Hutch. (a shrub or small tree indigenous to Ghana) with petroleum gave seven dammarane triterpenes. The two compounds were identified as common lupeol $\mathbf{2 3 4}$ and $\beta$-amyrin 211. Five of them were separated by column chromatography with silica gel and circular preparative thin-layer chromatography. After purification epilupeol 235, cabraleadiol 3-acetate 236, cabraleone 237, cabraleadiol 238 and isofouquierone 239 (ref. ${ }^{121}$ ). Both the acetate and isofouquierone appear to be new compounds.
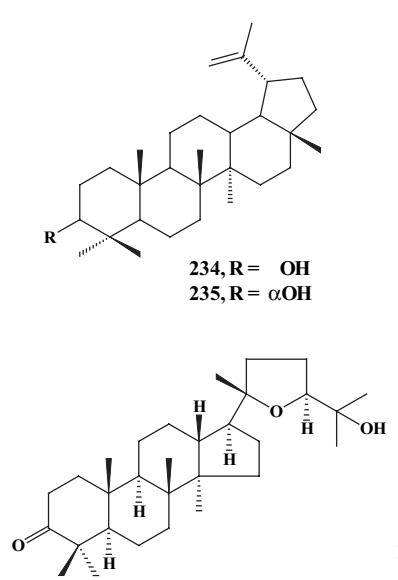

237
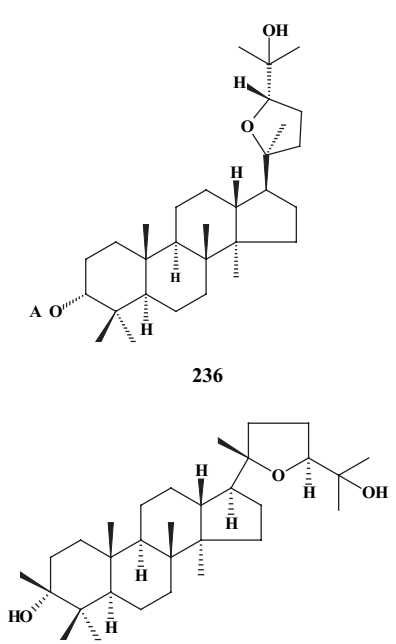

238

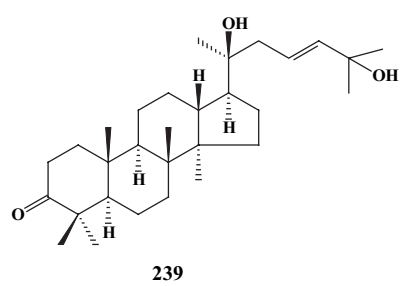

In the essential oil of Commiphora quadricincta a large number of the compounds were identified by GCMS and the following compounds with retention times of authentic samples (Table 6). A significant number of the compounds identified were terpenoids. Volatiles collected before the rains were comparatively richer, particularly in the more volatile fractions ${ }^{122}$.
Table 6. Compounds identified in the essential oil of $C$. quadricincta (evidence by MS and retention time).

\begin{tabular}{|c|c|c|}
\hline Compound & $\begin{array}{c}\text { Before } \\
\text { rains }\end{array}$ & $\begin{array}{l}\text { After } \\
\text { rains }\end{array}$ \\
\hline$\alpha$-pinene 1 & + & - \\
\hline camphene $\mathbf{2 4 0}$ & + & - \\
\hline$\beta$-pinene 196 & + & + \\
\hline o-xylene 241 & - & + \\
\hline m-xylene 242 & + & + \\
\hline p-xylene 243 & - & + \\
\hline$\beta$-myrcene 244 & + & - \\
\hline limonene 2 & + & + \\
\hline$\alpha$-phellandrene 148 & + & - \\
\hline (E,E)2,4-nonadienal 245 & + & + \\
\hline$\beta$-ocimene 26 & + & + \\
\hline 4-carene 246 & + & - \\
\hline styrene 247 & - & + \\
\hline phenylacetaldehyde & - & + \\
\hline$\alpha$-ocimene 248 & - & + \\
\hline p-cymene 45 & + & + \\
\hline$\alpha$-terpinolene 96 & + & + \\
\hline 4-nonanone & + & - \\
\hline 6-methyl-5-hepten-2-one $\mathbf{2 4 9}$ & + & + \\
\hline 3,4-dimethyl-octane & + & - \\
\hline 1-hexanol & - & + \\
\hline nonanal & + & - \\
\hline 1-heptanol & - & + \\
\hline$\alpha$-cubebene 43 & + & + \\
\hline linalool 153 & + & + \\
\hline copaene 53 & + & + \\
\hline (Z)- $\beta$-farnesene 89 & + & + \\
\hline linalyl acetate $\mathbf{2 5 0}$ & - & + \\
\hline caryophyllene 56 & + & + \\
\hline (+)-aromadendrene 251 & + & + \\
\hline alloaromadendrene 58 & + & + \\
\hline (E)- $\beta$-farnesene 89 & + & + \\
\hline ledene 252 & - & + \\
\hline$\gamma$-cadinene 64 & + & + \\
\hline$\beta$-cedrene 253 & + & - \\
\hline$\alpha$-farnesene 254 & - & + \\
\hline$\alpha$-guaiene 63 & + & + \\
\hline (E)-isoeugenol 255 & + & - \\
\hline
\end{tabular}


Table 7. Composition of the essential oil in the oleo-resin of Commiphora tenuis.

\begin{tabular}{|c|c|}
\hline Compound & Area \% \\
\hline$\alpha$-thujene 195 & 8.94 \\
\hline$\alpha$-pinene 1 & 60.84 \\
\hline camphene 240 & 0.26 \\
\hline sabinene 96 & 6.29 \\
\hline$\beta$-pinene 196 & 8.79 \\
\hline$\beta$-myrcene 61 & 1.80 \\
\hline 3-carene 97 & 3.66 \\
\hline p-cymene 45 & 0.90 \\
\hline$\beta$-thujene 257 & 0.91 \\
\hline limonene 2 & 5.52 \\
\hline cis- $\beta$-ocimene 258 & 0.15 \\
\hline trans- $\beta$-ocimene 26 & $<0.1$ \\
\hline$\gamma$-terpinene 259 & $\operatorname{tr}$ \\
\hline$\alpha$-pinene-epoxide $\mathbf{2 6 0}$ & $\operatorname{tr}$ \\
\hline$\alpha$-thujone 261 & $\operatorname{tr}$ \\
\hline$\alpha$-campholenal 262 & $\operatorname{tr}$ \\
\hline trans-verbenol 263 & $\operatorname{tr}$ \\
\hline verbenol 263 & $\operatorname{tr}$ \\
\hline pinocarvone 264 & $\operatorname{tr}$ \\
\hline p-mentha-1,5-dien-8-ol* 265 & $\operatorname{tr}$ \\
\hline p-mentha-1(7)-dien-8-ol* 266 & $\operatorname{tr}$ \\
\hline terpinen-4-ol 197 & $\operatorname{tr}$ \\
\hline p-cymen-8-ol 267 & $\operatorname{tr}$ \\
\hline myrtenal 268 & $\operatorname{tr}$ \\
\hline$\alpha$-terpineol 46 & $\operatorname{tr}$ \\
\hline myrtenol 269 & $\operatorname{tr}$ \\
\hline bornyl acetate $\mathbf{1 5 1}$ & $\operatorname{tr}$ \\
\hline eucarvone 270 & $\operatorname{tr}$ \\
\hline copaene $\mathbf{5 3}$ & 0.26 \\
\hline$\beta$-bourbonene 44 & $\operatorname{tr}$ \\
\hline$\beta$-elemene 39 & 1.07 \\
\hline$\beta$-caryophyllene 56 & $<0.1$ \\
\hline humulene derivative & $\operatorname{tr}$ \\
\hline alloaromadendrene $\mathbf{5 8}$ & $\operatorname{tr}$ \\
\hline$\beta$-gurjunene 271 & $\operatorname{tr}$ \\
\hline$\beta$-selinene 38 & $\operatorname{tr}$ \\
\hline$\alpha$-selinene 62 & $\operatorname{tr}$ \\
\hline$\alpha$-muurolene 272 & $\operatorname{tr}$ \\
\hline$\delta$-cadinene 65 & $\operatorname{tr}$ \\
\hline
\end{tabular}<smiles>C1CC2CC1C2</smiles>

240<smiles>C=CC(=C)CCCC(C)/C=C\CC1CCCCC1</smiles>

$246 \quad 247$<smiles>CCCCc1ccccc1C</smiles>
241<smiles>Cc1cccc(C)c1</smiles><smiles>Cc1ccc(CC2CC3CCC2C3)cc1</smiles>
243

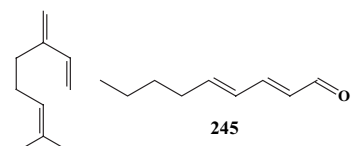<smiles>C=C1CCC2(C)C(C)(C)CCC2(C)C1C</smiles>

251
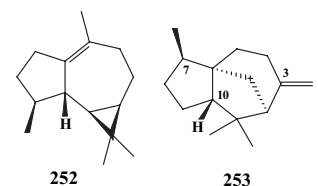<smiles>C=CC(C)=CCCC(C)CCCC(C)C</smiles><smiles>C/C=C\c1ccc(C)c(N(C)C)c1</smiles>

An exudate from Commiphora tenuis was collected in Ethiopia. After removal of the gum from the gum-resin and column chromatography four free triterpenes. The main triterpene was characterized as 3 $\beta$-O-acetoxyolean-12-en28-oic acid 256 (ref. ${ }^{123}$ ). After steam distillation the oil was taken up in n-pentane and analyzed by GC and GC-MS. Composition of the essential oil in the oleo-resin was as follows ( 37 compounds were identified - Table 7).

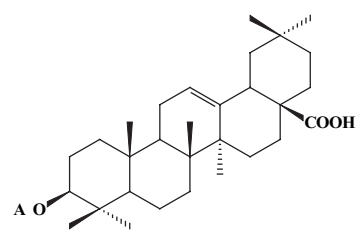

256
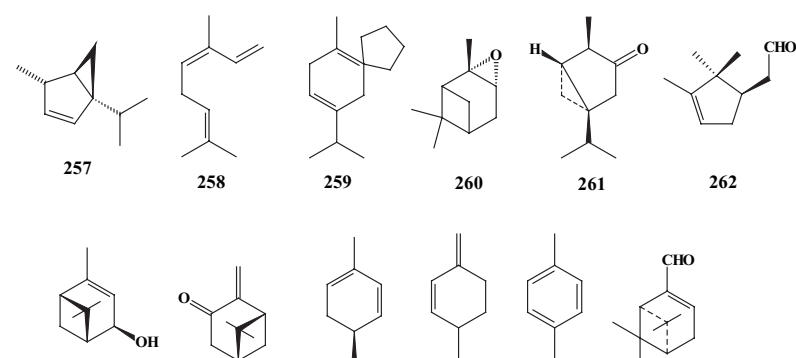<smiles>CC1C2CCC1C(=O)C2</smiles><smiles>CC1=CCC(C(C)(C)C)CC1</smiles><smiles>C=C1C=CC(C(C)(C)C)CC1</smiles><smiles>CCC1C2CC3CC(C3)C12</smiles><smiles>CC1CCC=C2CCC3C(C)C3C21</smiles>

271<smiles>CC1=CC2(CCCC2(C)C)C(C)CCC1C(C)C</smiles>

It was shown that several compounds which were previously reported to occur in myrrh are not present in true myrrh but originate from adulterant resins of other Commiphora species. This is also the case of 2methoxy-8,12-epoxygermacra-1(10),7,11-trien-6-one with 
stereochemistry as (1(10)E,2 R*,4R*)-2-methoxy-8,12-epoxygermacra-1(10),7,11-trien-6-one 22 and furanodienone with stereochemistry as (1(10)E,4E)-8,12-epoxygermacra1(10),4,7,11-tetraen-6-one 18 (ref. ${ }^{124}$ ). These compounds are obtained from the resin of other Commiphora species, namely $C$. sphaerocarpa, $C$. holtziana and $C$. kataf. In this work both compounds were isolated from petrol extract of the resin of $C$. sphaerocarpa and analyzed by X-ray crystallography and NMR for stereochemistry (are given ${ }^{13}$ C-NMR spectral data of furanodiene).

Very little is known about the chemistry of resins derived from others than usually studied Commiphora species, of which there are more than 50 in Ethiopia ${ }^{125}$.

Commiphora erlangeriana, occurring in Ethiopia and Somalia is known as "dhunkal". "Dhunkal" resin is toxic to humans and animals. However, the fruits are edible and sold in markets during rainy seasons. The powder resin was extracted with a mixture of methanol - ethyl acetate. After column chromatography four new lignans were identified in extract, two of the polygamain-type, named erlangerin A 273 (the most abundant compound - $41 \%$ ) and erlangerin B 274, and two related to podophyllotoxin, named erlangerin C 275 and erlangerin D 276 (ref. ${ }^{126}$ ).

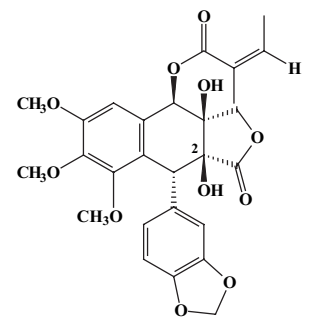

273

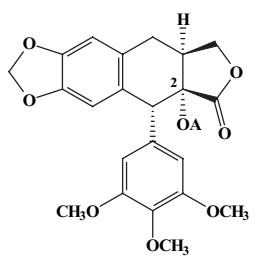

275

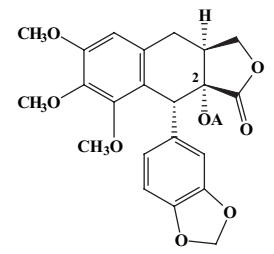

274

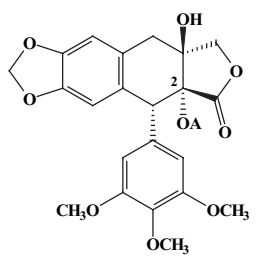

276
As the resin of Commiphora erlangeriana is known to be poisonous to humans and animals and has traditionally been used as an arrow poison, the recently found four erlangerins (A to D) were studied for their toxicity to mammalian cells. Two human (HeLa and EAhy926) and two murine (L929 and RAW 264.7) cell lines were used for toxicity assays. As assessed by the MTT assay, the effects of erlangerin $\mathrm{C}$ and $\mathrm{D}$ closely follow the activity profile of podophyllotoxin: they induced a concentration-dependent cytotoxicity in the murine macrophage cells (RAW 264.7) and a cytostatic effect in HeLa, EAhy926 and L929 cells. In contrast, erlangerins $A$ and $B$ suppressed cell viability at relatively higher concentrations $\left(\mathrm{EC}_{50}\right.$ values higher than $3 \mu \mathrm{M}$ as compared with $\mathrm{nM}$ concentration range for erlangerins $\mathrm{C}$ and $\mathrm{D}$ and podophyllotoxin) and their ac- tivity appears to be consistent with a cytotoxic mode of action in all cell lines studied ${ }^{127}$.

A new 5-methylchromone glycoside, named 7-O-methylaloeresin A (2-acetonyl-8-C- $\beta$-D[2'-O-(E)-4-hydroxycinna moyl]glucopyranosyl-7-methoxy-5-methylchromone) 277, was isolated from Commiphora socotrana (Burseraceae) ${ }^{128}$. Its structure was elucidated by spectroscopic data (MS, $\mathrm{UV},{ }^{1} \mathrm{H}$ - and ${ }^{13} \mathrm{C}-\mathrm{NMR}$ ).<smiles>COc1cc(C)c2c(=O)cc(CC(C)=O)oc2c1C(OC(=O)/C=C/c1ccc(O)cc1)C(CO)C(O)CO</smiles>

Volatile oils obtained by the steam distillation of aromatic resin with attractive odour from Boswellia neglecta, Commiphora africana, Commiphora campestris and Commiphora ogadensis have been examined by capillary GC and GC/MS. In each case the volatile oils appeared entirely monoterpenoid in constitution (Table 8). All four oils were generally characterized by high concentration of $\alpha$-pinene 1. Other constituents that were important markers of individual species included $\alpha$-thujene 195 (B. n., $C$. a.), sabinene 96 (C. c.), myrcene 52, car-3-ene 97 (C. o.) and p-cymene 45 (B. n., C. a. $)^{129}$.

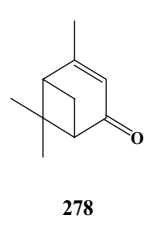

Bioassay-guided fractionation of a crude extract from Commiphora africana led to the isolation of the dihydroflavonol glucoside phellamurin 279 (ref. ${ }^{130}$ ).
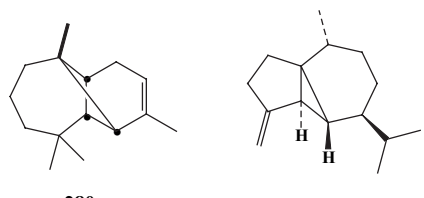

281
Samples of the liquid resin obtained spontaneously on cutting the woody parts of Commiphora terebinthina Vollesen (which occurs widely in northern Kenya and southern Ethiopia) and Commiphora cyclophylla Chiov. (occurs in southern Ethiopia) were examined. Both consist primarily of monoterpene hydrocarbons (no oxygenated derivatives were detected) with limonene 2 as the major component; the resin from $C$. $t$. was richer in sesquiterpenes (Table 9) ${ }^{131}$. 
Table 8. Concentration (\%) ranges of 12 monoterpenes in the volatile portion of the resins.

\begin{tabular}{|c|c|c|c|}
\hline Terpene & C. africana & C. campestris & C. ogadensis \\
\hline$\alpha$-thujene 195 & $3.9-42.4$ & - & $0-1.3$ \\
\hline$\alpha$-pinene 1 & $23.8-67.2$ & $32.6-83.0$ & $37.1-68.8$ \\
\hline camphene $\mathbf{2 4 0}$ & $0-2.4$ & $0-3.1$ & - \\
\hline sabinene 96 & $0-10.4$ & $1.0-37.3$ & $0-1.0$ \\
\hline$\beta$-pinene 196 & $4.2-12.1$ & $2.8-9.7$ & $1.1-2.3$ \\
\hline myrcene 52 & $0-2.1$ & - & $3.0-38.6$ \\
\hline $\begin{array}{l}\alpha \text {-phellandrene } \\
150\end{array}$ & -* $^{*}$ & - & - \\
\hline car-3-ene 97 & $0-1.7$ & - & $8.6-16.8$ \\
\hline p-cymene 45 & $0-28.0$ & $0-3.3$ & - \\
\hline limonene 2 & $0-8.6$ & $0-.8$ & $2.6-2.7$ \\
\hline terpinen-4-ol 197 & $0-13.1$ & $0-14.4$ & - \\
\hline verbenone 278 & $0-7.1$ & $0-3.0$ & - \\
\hline
\end{tabular}

* Present in two West African samples from Bourkina Faso

Table 9. Relative concentrations (\%) of volatile components of the resins.

\begin{tabular}{|l|c|c|}
\hline \multicolumn{1}{|c|}{ Compound } & C. terebinthina & C. cyclophylla \\
\hline$\alpha$-thujene 195 & - & 11.9 \\
$\alpha$-pinene 1 & 5.7 & 12.0 \\
sabinene 96 & 4.7 & 12.1 \\
$\beta$-pinene 196 & 0.6 & 1.9 \\
myrcene 52 & 1.4 & 2.0 \\
decane & 0.5 & - \\
car-3-ene 97 & 0.5 & 1.8 \\
limonene 2 & 50.4 & 46.9 \\
$\delta$-elemene 41 & 0.2 & - \\
longipinene 280 & 0.8 & - \\
$\alpha$-cubebene 43 & 3.9 & - \\
$\beta$-elemene 39 & 3.0 & 0.7 \\
t-caryophyllene 56 & 1.4 & 0.1 \\
$\beta$-cubebene 281 & 11.1 & 0.2 \\
$\alpha$-muurolene 272 & 3.7 & - \\
$\delta$-cadinene 65 & 1.6 & - \\
\hline
\end{tabular}

The resins from the African Burseraceae are important items of commerce, as glues, tick repellents, medicinals and perfumes. The content compounds of these resins are not yet well identified. Three known - (1E)-3-methoxy-8,12-epoxygermacra-1,7,10,11-tetraen-6-one 35, rel-2Rmethyl-5S-acetoxy-4R-furanogermacr-1(10)Z-en-6-one 34 and $\left(1(10) E, 2 R^{*}, 4 R^{*}\right)-2$-methoxy-8,12-epoxygermacra1(10),7,11-trien-6-one 22 - and one novel furanogermacrenes have been isolated and identified from the ethanolic extract of a resinous exudates (a commercial sample) of Commiphora holtziana from Kenya. The structure of the known compounds was determinated by comparison of ${ }^{1} \mathrm{H}$ - and ${ }^{13} \mathrm{C}-\mathrm{NMR}$ spectra with those already published. The structure of the novel compound was determined as 1,2-epoxyfurano-10(15)-germacren-6-one 283, using spectrometric techniques. Some previous ${ }^{13} \mathrm{C}-\mathrm{NMR}$ assignments for the known compounds were corrected or clarified $^{132}$.

$\beta$-sitosterol 112, m.p. $138^{\circ}$, and cedrelone 282, m.p. $203-4^{\circ}$, were isolated from hexane extracts of Balsamodendron pubescens roots as well as a 4,7-dimethoxy-5-methylcoumarin characterized as siderin $\mathbf{2 8 4}$ $\left(\right.$ ref. $\left.{ }^{133}\right)$. A novel synthesis of siderin and 6,8-dimethoxy4-methylcoumarin was given.

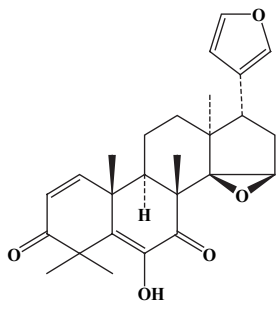

282

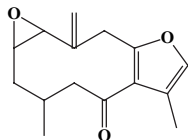

283<smiles></smiles>

284
The resin of Commiphora confusa afforded two new dammarane triterpenes, $(3 R, 20 S)$-3,20-dihydroxydammar24-ene 285 and ( $3 R, 20 S)$-3-acetoxy-20-hydroxydammar-24ene 286 along with the known triterpenes, cabraleadiol 3-acetate 236 and $\alpha$-amyrin 287 (ref. ${ }^{134}$ ).

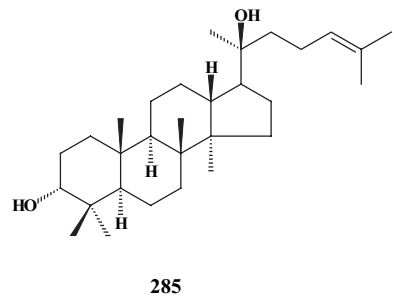

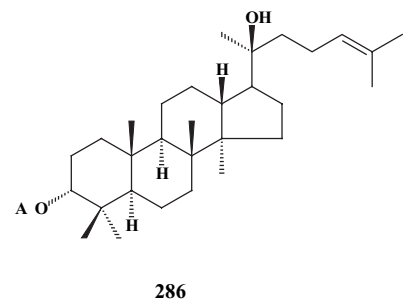

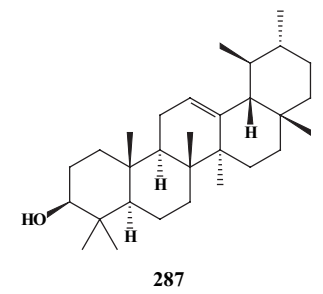

Color and precipitation reactions proved the presence of condensed tannins and these were detected for the powdered bark and alcoholic extract of Commiphora angolensis, respectively. An unsuccessful attempt was made by using ascending paper chromatography to identify the phenolic compounds present. By elution of a fraction separated on a thick paper chromatogram with $\mathrm{HCl}-\mathrm{MeOH}$, ascending paper chromatography separated petunidin 3-rhamnoglucoside $\mathbf{2 8 8}$ (buthanol - acetic acid - water, $\mathrm{BuOH}-\mathrm{HCl}$ and $1 \% \mathrm{HCl})^{135}$. 


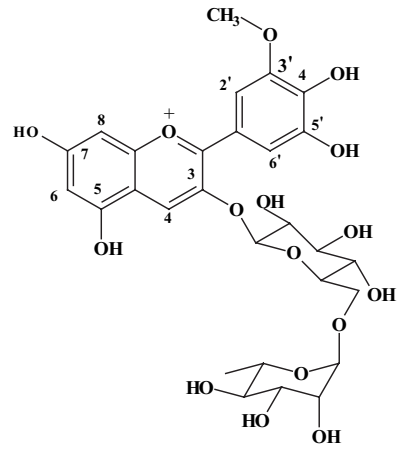

288

Seeds of Commiphora guillaumini Perr. tree were collected at Madagascar. The frozen arils were ground and extracted with cyclohexane. Supercritical fluid chromatography - atmospheric pressure chemical ionization mass spectrometry was employed for the determination of the lipid composition in the arils. From tri- and diacylglycerols tripalmitoylglycerol (PPP), PPS, PPO, PPL, POS, POO, PLO, LSS, POLn, OSS, OOS, OOO, OOL, OLL, LLL, OP and OO $(\mathrm{P}=$ palmitoyl, $\mathrm{S}=$ stearoyl, $\mathrm{O}=$ oleoyl, $\mathrm{L}=$ linoleoyl, $\mathrm{Ln}=$ linolenoyl) were identified. From identified triacylglycerols and diacylglycerols are possible all positional permutations, since it is not possible to determine the positional isomers of the glycerols by MS. The assigned structure represents one of the possible positional permutations. The presence of the known ant attractant 1,2-dioleoylglycerol in arils of the seeds of $C$. guillaumini was confirmed ${ }^{136}$.

The steam distilled resin residue of Commiphora confuse samples obtained from well identified trees (around Saltlik, Kenya) has yielded after acetone extraction and following column chromatography on silicagel four novel dammarane triterpenes characterised as (20S)-3 3 -acetoxy$12 \beta, 16 \beta$-trihydroxydammar-24-ene $\mathbf{2 8 9}$, (20S) $12 \beta, 16 \beta$ trihydroxydammar-24-ene-3 $\beta$-O- $\beta$-glucopyranoside 290, (20S)-3 $\beta$-acetoxy-12 $\beta, 16 \beta, 25$-tetrahydroxydammar-23-ene 291, and (20S)-3 $\beta, 12 \beta, 16 \beta, 25$-pentahydroxydammar-23-ene 292. The known compounds $\beta$-amyrin 211, $3 \beta$-amyrinacetate, 2-methoxyfuranodienone, 2-acetoxyfuranodienone,

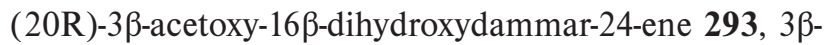
hydroxydammar-24-ene 294, 3 $\beta$-acetoxydammar-24-ene

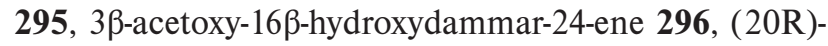
$3 \beta, 16 \beta$-trihydroxydammar-24-ene 297, and $\beta$-sitosterol 112 were also isolated from the same extract. The structures of the compounds were determined using spectroscopic, physical, and chemical methods ${ }^{137}$.

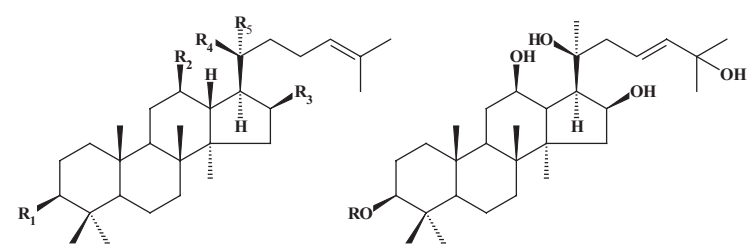

$\begin{array}{llcccll} & \mathbf{R}_{1} & \mathbf{R}_{2} & \mathbf{R}_{3} & \mathbf{R}_{4} & \mathbf{R}_{5} & \\ 289 & \text { OA } & \text { OH } & \text { OH } & \text { OH } & \mathrm{CH}_{3} & 296 \quad \mathbf{R}=\mathbf{A} \\ 290 & \text { O-glu } & \text { OH } & \text { OH } & \text { OH } & \mathrm{CH}_{3} & 297 \mathrm{R}=\mathbf{H} \\ 291 & \text { OA } & \mathbf{H} & \text { OH } & \mathrm{CH}_{3} & \text { OH } & \\ 292 & \text { OH } & \text { H } & \text { H } & \mathbf{H} & \mathrm{CH}_{3} & \\ 293 & \text { OA } & \text { H } & \text { H } & \text { H } & \mathrm{CH}_{3} & \\ 294 & \text { OA } & \text { H } & \text { OH } & \text { H } & \mathrm{CH}_{3} & \\ 295 & \text { OH } & \text { H } & \text { OH } & \mathrm{CH}_{3} & \text { OH } & \end{array}$

\section{REFERENCES}

1. Pernet R: (1972) Phytochimie des Burseracees. Lloydia 35, 280287.

2. Thulin M. (2000) Ten new species of Commiphora (Burseraceae) from Somalia. Nord J Bot 20, 395-411.

3. Tucker AO. (1986) Frankincense and Myrrh. Econ Bot 40, 425433.

4. Guenther E. (1950) The Essential Oils. Vol. 4. Van Nostrand, New York

5. Mincione E, Iavarone C. (1972) Terpeni dalla Commifera mirra Arabica. Nota I. Chim Ind (Milan) 54, 424-425.

6. Wilson RA, Mookherjee BD. (1983) Characterization of aroma donating components of myrrh. Proceedings of $9^{\text {th }}$ International Congress of Essential Oils, Singapore, 13-17 March, paper no. 400, pp. 1-10, Book 4. Singapore: Essential Oils Association of Singapore.

7. Ishii H, Tozyo T, Nakamura M, Takeda K. (1968) Components of the root of lindera strychnifolia Vill-XIII : Structure of isogermafurene and lineroxide. Tetrahedron 24, 625-631.

8. Hikino H, Agatsuma K, Takemoto T. (1968) Structure of curzerenone, epicurzerenone, and isofuranogermacrene (curzerene). Tetrahedron Lett 9, 2855-2858.

9. Hikino H, Agatsuma K, Konno C, Takemoto T. (1970) Sesquiterpenoids. 35. Structure of furanodiene and isofuranogermacrene (curzerene) Chem Pharm Bull 18, 752-755.

10. Malingre TM. (1975) Curcuma xanthorrhiza, Temoe Lawak, A Plant with Cholagog Activity. Pharm Weekbl 110, 601-610.

11. Hikino H, Agatsuma K, Takemoto T. (1968) Furanodiene, a precursor of furan-containing sesquiterpenoids. Tetrahedron Lett 9 , 931-933.

12. Hikino H, Konno C, Agatsuma K, Takemoto T, Horibe I, Tori K, Ueyama M, Takeda K. (1975) Sesquiterpenoids .47. Structure, configuration, conformation, and thermal rearrangement of furanodienone, isofuranodienone, curzerenone, epicurzerenone, and pyrocurzerenone, sesquiterpenoids of Curcuma-zedoaria. J Chem So. Perk T 1, 478-484.

13. Hikino H, Hikino Y, Yosioka I. (1962) Structure and autoxidation of atractylon. Chem Pharm Bull 10, 641-642.

14. Takeda K, Minato H, Miyawaki M, Ishikawa M. (1964) Components of root of Lindera strychnifolia VILL .9. Structures of lindestrene and linderene acetate. Tetrahedron 20, 2655-2663.

15. Takeda KI, Ishii H, Tozyo T, Minato H. (1969) Components of root of Lindera strychnifolia VILL. 16. Isolation of lindenene showing a new fundamental sesquiterpene skeleton, and its correlation with linderene. J Chem Soc C (14), 1920-1921.

16. Fukushima S, Kuroyana M, Ueno A, Akahori Y, Saiki Y. (1970) Structure of curzerenone, a new sesquiterpene from Curcuma-zedoaria. Yakugaku Zasshi 90, 863-869. 
17. Uematsu S, Akahori Y, Fukushima S, Saiki Y, Ueno A, Kuroyana M. (1970) A nuclear magnetic resonance study of curzerenone. Chem Pharm Bul 18, 1118-1123.

18. Monti D, Manitto P, Tagliapietra S, Dada G, Speranza G. (1986) The absolute stereochemistry of two furanogermacranes of myrrh as determined by the circular dichroism exciton chirality method. Gazz Chim Ital 116, 303-306.

19. Ma X, Yu X, Zheng Z, Mao J. (1992) Investigation of volatile composition in frankincense and myrrh using analytical supercritical fluid extraction technique. Yaowu Fenxi Zazhi 12, 83-86.

20. Yu X, Ma X, Ding X. (1993) GC/ITD study of major constituents of the extracts of myrrh and Curcuma zedoaria. Fenxi Ceshi Xuebao $12,8-13$.

21. Wiendl RM, Franz G. (1994) Myrrh. New chemistry of an old plant drug. Dtsch Apoth Ztg 134, 27-29, 31-32.

22. Wang W, Zhu Y, Qin X, Tian J. (1995) Analysis of the chemical constituents of essential oil of MYRRHA from Kenia. Yaowu Fenx Zazhi 15, 33-36

23. Jingai T, Shangwei S. (1996) Studies on the constituents of essential oil of imported Myrrh and gum opoponax. Zhongguo Zhongyao Zazhi 21, 235-237.

24. Edwards HGM, Falk MJ. (1997) Fourier-transform Raman spectroscopic study of frankincense and myrrh. Spectrochim Acta A 53, 2393-2401.

25. Brody RH, Edwards HGM, Pollard AM. (2002) Fourier transformRaman spectroscopic study of natural resins of archaeological interest. Biopolymers 67, 129-141.

26. Hough L, Jones JKN, Wadman WH. (1952) Some observations on the Constitution of Gum Myrrh. J Chem Soc 796-800.

27. Jones JKN, Nunn JR (1955). The Constitution of Gum Myrrh. Part II. J Chem Soc 3001-3004.

28. Mincione E, Iavarone C. (1972) Terpeni dalla Commifera mirra Arabica. Nota II. Chim Ind (Milan) 54, 525-527.

29. Maradufu A. (1982) Furanosesquiterpenoids of Commiphora erythraea and C. myrrh. Phytochemistry 21, 677-680.

30. Provan GJ, Gray A I, Waterman PG. (1987) Chemistry of the Burseraceae. Part 5. Sesquiterpenes from the myrrh-type resins of some Kenyan Commiphora species. Flavour Fragrance J 2, 109-13.

31. Ognjanov I, Ivanov D, Herout V, Horák M, Plíva J, Šorm F. (1958) On terpenes. LXXXVIII. The structure of germacrone, the crystalline constituent of Bulgarian 'zdravets' oil. Collect Czech Chem Commun 23, 2033-2045.

32. Ulubelen A, Gören N, Jakupovic J. (1986) Germacrane derivatives from the fruits of Smyrnium creticum. Phytochemistry 26 312-313.

33. Rücker G, Deassisba GA, Bauer L. (1971) Structure of isofuranodiene from Stenocylax-michelii (Myrtaceae). Phytochemistry 10, 221-224.

34. Maradufu A, Warthen JD. (1988) Furanosesquiterpenoids from Commiphora myrrh oil. Plant Sci 57, 181-184.

35. Demissew S. (1993) A description of some essential oil bearing plants in Ethiopia and their indigenous uses. J Essent Oil Res 5, 465-479.

36. Blay G, Cardona L, Garcia B, Pedro JR, Sanchez J.J (1996) Stereoselective Synthesis of 8,12-Furanoeudesmanes from Santonin. Absolute Stereochemistry of Natural Furanoeudesma-1,3-diene and Tubipofurane. J Org Chem 61, 3815-3819.

37. Ubillas RP, Mendez CD, Jolad SD, Luo J, King SR, Carlson TJ, Fort DM. (1999) Antihyperglycemic furanosesquiterpenes from Commiphora myrrha. Planta Med 65, 778-779.

38. Zhu N, Kikuzaki H, Sheng S, Sang S, Rafi MM, Wang M, Nakatani N, DiPaola RS, Rosen RT, Ho CT. (2001) Furanosesquiterpenoids of Commiphora myrrha. J Nat Prod 64, 1460-1462.

39. Dekebo A, Dagne E, Sterner O. (2002) Furanosesquiterpenes from Commiphora sphaerocarpa and related adulterants of true myrrh Fitoterapia 73, 48-55.

40. Yoshihara K, Ohta Y, Sakai T, Hirose Y. (1969) Germacrene D a key intermediate of cadinene group compounds and bourbonenes. Tetrahedron Lett (27), 2263-2264.
41. Niwa M, Iguchi M, Yamamura S. (1980) Co-occurrence of (-)germacrene-D and (+)-germacrene-D in Solidago-altissima L - determination of the optical-rotation of optically pure germacrene-D. Chem Pharm Bull 28, 997-999.

42. Nishimura K, Shinoda N, Hirose Y. (1969) A new sesquiterpene, bicyclogermacrene. Tetrahedron Lett 10, 3097-3100.

43. Nishimura K, Horibe I, Tori K. (1973) Conformations of 10-membered rings in bicyclogermacrene and isobicyclogermacrene. Tetrahedron 29, 271-274.

44. Morteza-Semnani K, Saeedi M. (2003) Constituents of the essential oil of Commiphora myrrha (Nees) Engl. var. molmol. J Essent Oil Res 15, 50-51.

45. Baser K.HC, Demirci B, Dekebo A, Dagne E. (2003) Essential oils of some Boswellia spp., Myrrh and Opopanax. Flavour Fragrance J $18,153-156$

46. Zhu N, Sheng S, Sang S, Rosen RT, Ho C-T. (2003) Isolation and characterization of several aromatic sesquiterpenes from Commiphora myrrha. Flavour Fragrance J 18, 282-285.

47. Brieskorn CH, Noble P. (1980) Drei neue furanogermacrene aus myrrhe. Tetrahedron Lett 21, 1511-1514.

48. Brieskorn CH, Noble P. (1983) Two furanoeudesmanes from the essential oil of myrrh. Phytochemistry 22, 187-189.

49. Brieskorn CH, Noble P. (1983) Furanosesquiterpenes from the essential oil of myrrh, Phytochemistry 22, 1207-1211.

50. Wiendl RM, Müller BM, Franz G. (1995) Proteoglycans from the gum exudate of myrrh. Carbohyd Polym 28, 217-226.

51. Dolara P, Luceri C, Ghelardini C, Monserrat C, Aiolli S, Luceri F, Lodovici M, Menichetti S, Romanelli MN. (1996) Analgesic effects of myrrh. Nature 379, 29.

52. Dolara P, Corte B, Ghelardini C, Pugliese AM, Cerbai E, Menichetti S, Lo Nostro A. (2000) Local anaesthetic, antibacterial and antifungal properties of sesquiterpenes from myrrh. Planta Med 66, 356-358.

53. AbdulGhani AS, Amin R. (1997) Effect of aqueous extract of Commiphora opobalsamum on blood pressure and heart rate in rats. $\mathrm{J}$ Ethnopharmacol 57, 219-222.

54. Ikeda RM, Stanley WL, Vannier SH, Spitler EM. (1962) The monoterpene hydrocarbons composition of some essential oils. J Food Sci 27, 455-458.

55. Nigam IC, Levi L. (1966) Essential oils and their constituents. XXXII. Gas chromatography of sesquiterpene hydrocarbons. J Chromatogr 23, 217-226.

56. Wenninger JA, Yates RL, Dolinsky M. (1967) High resolution infrared spectra of some naturally occurring sesquiterpene hydrocarbons. J Assoc Off Analyst Chem 50, 1313-1335.

57. Regan AF, Andrews BR. (1967) Gas chromatography of sesquiterpene hydrocarbons. J Chromatogr 31, 209

58. Nigam IC, Neville GA. (1968) Essential oils and their constituents. Part XLI. Identification of sesquiterpene hydrocarbons in oil of opopanax. J Chromatogr 34, 85-88.

59. Wenninger JA, Yates RL. (1969) Constituents of Opoponax Oil: Sesquiterpene hydrocarbons. J Assoc Off Analyst Chem 52, 11551161.

60. Delay F, Ohloff G. (1979) Syntheses and absolute configuration of (E)- and (Z)- $\alpha$-bisabolenes. Helv Chim Acta 62, 369-377.

61. Bhati A. (1950) Essential oil from the resin of Commiphora mukul. J Indian Chem Soc. 27, 436-440.

62. Bose S, Gupta C. (1964) Structure of Commiphora mukul Gum: Part I - Nature of Sugars Present \& the Structure of the Aldobiouronic Acid. Indian J Chem 2, 57-60.

63. Bose S, Gupta C. (1964) Structure of Commiphora mukul Gum: Part III - Methylation \& Periodate Oxidation Studies. Indian J Chem 4, 87-89.

64. Bose S, Gupta C. (1964) Structure of Commiphora mukul Gum: Part II - Structure of the Degraded Gum. Indian J Chem 2, 156158.

65. Amjad AM, Mashooda H. (1967) Chemical investigation of Commiphora mukul. Pakistan J Sci Ind Res 10, 21-23.

66. Arora RB, Kapoor V, Gupta SK, Sharma RC. (1971) Isolation of a crystalline steroidal compound from Commiphora mukul \& its anti-inflammatory activity. Indian J Exp Biol 9, 403-404. 
67. Arora RB, Taneja V, Sharma RC, Gupta SK. (1972) Anti-inflammatory studies on a crystalline steroid isolated from Commiphora mukul. Indian J Med Res 60, 929-931.

68. Rücker G. (1972) Über monocyclische Diterpene aus dem indischen Guggul-Harz (Commiphora mukul). Arch. Pharm. (Weinheim) 305, 486-493.

69. Raldugin VA, Shelepina OB, Sekatsis IP, Rezvukhin AI, Pentegova VA (1976) Configuration of C3 double bond and partial synthesis of allylcembrol. Khim Prir Soedin (1), 108-109.

70. Patil VD, Nayak UR, Dev S. (1972) Chemistry of Ayurvedic crude drugs-I: Guggulu (resin from Commiphora mukul)-1: Steroidal constituents. Tetrahedron 28, 2341-2352.

71. Patil VD, Nayak UR, Dev S. (1973) Chemistry of ayurvedic crude drugs-II: Guggulu (resin from Commiphora mukul)-2: Diterpenoid constituents. Tetrahedron 29, 341-348.

72. Patil VD, Nayak UR, Dev S. (1973) Chemistry of ayurvedic crude drugs-III: Guggulu (resin from Commiphora mukul)-3 long-chain aliphatic tetrols, a new class of naturally occurring lipids. Tetrahedron 29, 1595-1598.

73. Purushothaman KK, Chandrasekharan S. (1976) Gugulsterols from Commiphora mukul (Burseraceae). Indian J Chem, Sect B 14B, 802-804.

74. Prasad RS, Dev S. (1976) Chemistry of ayurvedic crude drugs-IV: Guggulu (resin from commiphora mukul-4 absolute stereochemistry of mukulol. Tetrahedron 32, 1437-1441.

75. Bajaj AG., Dev S, Arnold E, Tagle B, Clardy J. (1981) The stereochemistry of guggulsterol-1. Tetrahedron Lett 22, 4623-4626

76. Kakrani HK. (1981) Flavonoids from the flowers of Commiphora mukul. Fitoterapia 52, 221-223.

77. Kakrani HK. (1982) Physicochemical examination of seed oil from Commiphora mukul Hook ex Stocks. Indian Drugs 19, 339-341.

78. Bajaj AG, Sukh DS. (1982) Chemistry of ayurvedic crude drugs-V: Guggulu (resin from commiphora mukul)-5 some new steroidal components and, stereochemistry of guggulsterol-I at C-20 and C-22. Tetrahedron 38, 2949-2954.

79. Kumar V, Dev S. (1987) Chemistry of ayurvedic crude drugs-VII: Guggulu (resin from Commiphora mukul). 6. absolute stereochemistry of guggultetrols. Tetrahedron 43, 5933-5948.

80. Satyavati GV. (1991) Guggulipid: A promising hypolipidaemic agent from gum guggul (Commiphora wightii). Economic and $\mathrm{Me}$ dicinal Plant Research, Volume 5. Plants and Traditional Medicine, 47-82.

81. Satyavati GV. (1988) Gum guggulu (Commiphora mukul)-the success story of an ancient insight leading to a modern discovery. Indian J Med Res 87, 327-35.

82. Sharma ML, Gour HN. (1988) Biochemical-components of Commiphora-wightii (Arnott) Bhand leaves infected with Phoma sp. Ann Arid Zone 27, 275-276.

83. Duwiejua M, Zeitlin IJ, Waterman PG, Chapman J, Mhango GJ, Provan G. J (1993) Anti-inflammatory activity of resins from some species of the plant family Burseraceae. Planta Med 59, 12-16.

84. Saxena VK, Sharma RN. (1998) Constituents of the essential oil from Commiphora mukul gum resin. J Med Arom Plant Sci 20, 55-56.

85. Mesrob B, Nesbitt C, Misra R, Pandey RC. (1998) High-performance liquid chromatographic method for fingerprinting and quantitative determination of E- and Z-guggulsterones in Commiphora mukul resin and its products. J Chromatogr B 720, 189-196.

86. Verma N, Singh SK, Gupta RC. (1998) Simultaneous determination of the stereoisomers of guggulsterone in serum by high-performance liquid chromatography. J Chromatogr B 708, 243-248.

87. Atta-ur-Rahman, Choudhary MI, Shaheen F, Ashraf M, Jahan S (1998) Microbial transformations of hypolipemic E-guggulsterone. J Nat Prod 61, 428-431.

88. Kimura I, Yoshikawa M, Kobayashi S, Sugihara Y, Suzuki M, Oominami H, Murakami T, Matsuda H, Doiphode VV. (2001) New triterpenes, myrrhanol A and myrrhanone A, from guggulgum resins, and their potent anti-inflammatory effect on adjuvantinduced air-pouch granuloma of mice. Bioorg Med Chem Lett 11, 985-989.
89. Matsuda H, Morikawa T, Ando S, Oominami H, Murakami T, Kimura I, Yoshikawa M. (2004) Absolute stereostructures of polypodane-type triterpenes, myrrhanol $\mathrm{A}$ and myrrhanone A, from guggul-gum resin (the resin of Balsamodendron mukul). Chem Pharm Bull 52, 1200-1203.

90. Matsuda H, Morikawa T, Ando S, Oominami H, Murakami T, Kimura I, Yoshikawa M (2004) Absolute stereostructures of polypodane- and octanordammarane-type triterpenes with nitric oxide production inhibitory activity from guggul-gum resins. Bioorg Med Chem 12, 3037-3046.

91. Sarkhel S, Yadava U, Prakas P, Jain GK, Singh A, Maulik PR. (2001) Guggulsterone E, a lipid-lowering agent from Commiphora mukul Acta Crystallogr E57, o285-o286.

92. Zhu N, Rafi MM, DiPaola RS, Xin J, Chin C-K, Badmaev V, Ghai G, Rosen RT, Ho C-T. (2001) Bioactive constituents from gum guggul (Commiphora wightii). Phytochemistry 56, 723-727.

93. Meselhy MR. (2003) Inhibition of LPS-induced NO production by the oleogum resin of Commiphora wightii and its constituents. Phytochemistry 62, 213-218.

94. Fatope MO, Al-Burtomani SKS, Ochei JO, Abdulnour AO, AlKindy M.Z, Takeda Y. (2003) Muscanone: a 3-O-(1",8"14"-trimet hylhexadecanyl)naringenin from Commiphora wightii. Phytochemistry 62, 1251-1255.

95. Francis JA.; Raja SN, Nair MG. (2004) Bioactive terpenoids and guggulusteroids from Commiphora mukul gum resin of potential anti-inflammatory interest. Chem Biodiversity 1, 1842-1853.

96. Provan GJ, Gray AI, Waterman PG. (1992) Mansumbinane derivatives from stem bark of Commiphora kua. Phytochemistry 31 , 2065-2068.

97. Manguro LOA, Mukonyi KM, Githiomi JK. (1996) Bisabolenes and furanosesquiterpenoids of Kenyan Commiphora kua resin. Planta Med 62, 84-85.

98. Battu GR, Zeitlin IJ, Gray AI, Waterman PG. (1999) Inhibitory actions on rat myeloperoxidease of molecules isolated from antiinflammatory extracts of Commiphora kua. Brit J Pharmacol 128, 274P Suppl. S.

99. Dekebo A, Dagne E, Hansen LK, Gautun OR, Arne J, Aasen AJ. (2002) Two octanordammarane triterpenes from Commiphora kua. Phytochemistry 59, 399-403.

100. Manguro LO, Ugi I, Lemmen P. (2003) Further Bisabolenes and Dammarane Triterpenes of Commiphora kua Resin. Chem Pharm Bull 51, 479-482.

101. Thomas AF, Müller JM. (1960) Triterpene acids from Commiphora glandulosa Schinz. Experientia 16, 62-64.

102. Thomas AF. (1961) The triterpenes of Commiphora - II. The structure of comic acid $\mathrm{C}$ and comic acid D. Tetrahedron 15 , 212-216.

103. Thomas AF, Heusler K, Müller JM. (1961) The triterpenes of Commiphora-III : The structure of commic acid E. Tetrahedron 16, 264-270.

104. Craveiro A, Corsano S, Proietti G, Strappaghetti G. (1983) Constituents of essential oil of Commiphora-guidotti. Planta Med 48, 97-98.

105. Claeson P, Andersson R, Samuelsson G (1991) T-cadinol - a pharmacologically active constituent of scented myrrh - introductory pharmacological characterization and high-field h-1-nmr and c-13nmr data. Planta Med 57, 352-356.

106. Andersson M, Bergendorff O, Shan RD, Zygmunt P, Sterner O. (1997) Minor components with smooth muscle relaxing properties from scented myrrh (Commiphora guidotti). Planta Med 63, 251-254.

107. Thulin M, Claeson P. (1991) The botanical origin of scented myrrh (bissabol or habak hadi). Econ Bot 45, 487-494.

108. Thomas AF, Willhalm B. (1964) The triterpenes of Commiphora IV mass spectra and organic analysis V mass spectroscopic studies and the structure of commic acids A and B. Tetrahedron Lett 5, 3177-3183.

109. Brieskorn CH, Noble P. (1982) Inhaltsstoffe des etherischen Öls der Myrrhe. II: Sesquiterpene und Furanosesquiterpene. Planta Med 44, 87-90. 
110. Cagnoli Bellavita B, Ceccherelli P, Damiani P. (1968) Cholesterol, campesterol, and $\beta$-sitosterol from a Commiphora abyssinica. Ann Chim (Rome) 58, 541-545.

111. Jessenne MG, Bezanger-Beauquesne L, Pinkas M, Trotin F. (1974) Gums of two gum resins, bdellium and galbanum. Plant Med Phytother 8, 241-249.

112. Ayedoun M.A, Moudachirou M, Tomi F, Casanova J. (1997) Identification by $13 \mathrm{C}$ NMR and by GC/MS of the principal components of essential oils from Xylopia aethiopica (dunal). Richard and of Commiphora africana from Benin. J Soc Quest-Afr Chi. 2, 29-35.

113. Ayedoun MA, Sohounhloue DK, Menut C, Lamaty G, Molangui T, Casanova J, Tomi F. (1998) Aromatic plants of Tropical West Africa. VI. $\alpha$-Oxobisabolene as main constituent of the leaf essential oil of Commiphora africana (A. Rich.) Engl. from Benin. J Essent Oil Res 10, 105-107.

114. Choudhury MK, Johnson EC, Agbaji AS. (2000) Chemical investigation of the bark of Commiphora africana (Burseraceae). Ind $\mathrm{J}$ Pharm Sci 62, 311-312.

115. Provan GJ, Waterman PG. (1985) Picropolygamain: a new ligand from Commiphora incise Resin. Planta Med 271-272.

116. Provan GJ, Waterman PG. (1986) The mansumbinanes: Octanordammaranes from the resin of Commiphora incise. Phytochemistry 25, 917-922.

117. Provan GJ, Waterman PG. (1988) Chemistry of the Burseraceae 10. Major triterpenes from the resins of commiphora-incisa and C. kua and their potential chemotaxonomic significance. Phytochemistry 27, 3841-3843.

118. McDowell PG, Lwande W, Deans SG, Waterman PG. (1988) Volatile resin exudate from stem bark of Commiphora rostrata: Potential role in plant defence. Phytochemistry 27, 2519-2521.

119. Lwande W, Hassanali A, Mcdowell PG, Moreka L, Nokoe SK, Waterman, PG. (1992) Constituents of Commiphora rostrata and some of their analogs as maize weevil, Sitophilus zeamais repellents. Insect Sci Its Appl 13, 679-683.

120. Fourie TG, Snyckers FO. (1989) A pentacyclic triterpene with anti-inflammatory and analgesic activity from the roots of Commiphora merkeri. J Nat Prod 52, 1129-1131.

121. Waterman PG, Ampofo S. (1985) Dammarane Triterpenes from the stem bark of Commiphora Dalzielii. Phytochemistry 24, 2925 2928.

122. Assad YOH, Torto B, Hassanali A, Njagi PGN, Bashir NHH, Mahamat H. (1997) Seasonal variation in the essential oil composition of Commiphora quadricincta and its effect on the maturation of immature adults of the desert locust, Schistocerca gregaria. Phytochemistry 44, 833-841.
123. Asres K, Tei A, Moges G, Sporer F, Wink M. (1998) Terpenoid composition of the wound-induced bark exudate of Commiphora tenuis from Ethiopia. Planta Med 64, 473-5.

124. Dekebo A, Dagne E, Hansen LK, Gautun OR, Aasen AJ. (2000) Crystal structures of two furanosesquiterpenes from Commiphora sphaerocarpa. Tetrahedron Lett 41, 9875-9878.

125. Vollesen K. 1989 In Burseraceae. Flora of Ethiopia. Hedberg I., Edwards S., Eds., Addis Ababa University Press, Addis Ababa, Vol. 3, pp. 442-478.

126. Dekebo A, Lang M, Polborn K, Dagne E, Steglich W. (2002) Four lignans from Commiphora erlangeriana. J Nat Prod 65, 1252-7.

127. Habtemariam S. (2003) Cytotoxic and cytostatic activity of erlangerins from Commiphora erlangeriana. Toxicon 41,723-727.

128. Blitzke T, Schmidt J, Masaoud M. (2001) 7-O-methylaloeresin A - a new chromone glycoside from Commiphora socotrana. Nat. Prod. Lett 15, 27-33.

129. Provan G.J, Gray AI, Waterman PG. (1987) Chemistry of the Burseraceae. Part 6. Monoterpene-rich resins from some Kenyan Burseraceae. Flavour Fragrance J 2, 115-118.

130. Ma J, Jones SH, Hecht, Sidney M. (2005) A Dihydroflavonol Glucoside from Commiphora africana that Mediates DNA Strand Scission. J Nat Prod 68, 115-117.

131. Abegaz B, Dagne E, Bates C,. Waterman PG. (1989) Chemistry of the Burseraceae. Part 12. Monoterpene-rich resins from two Ethiopian species of Commiphora. Flavour Fragrance J 4, 99-101.

132. Cavanagh IS, Cole MD, Gibbons S, Gray AI, Provan GJ, Waterman, PG. (1993) Chemistry of the Burseraceae. Part 16. A novel sesquiterpene, 1,2-epoxyfurano-10(15)-germacren-6-one, from the resin of Commiphora holtziana Engl. Flavour Fragrance $\mathbf{J} 8$, 39-41.

133. Balawant JJ, Hegde VR. (1979) Extractives of Balsamodendron pubescens: Stocks, Hook. Isolation and a new synthesis of siderin. Proc. - Indian Acad Sci, Sect A 88 A (Pt.1, No.3), 185-190.

134. Dekebo A, Dagne E, Curry P, Gautun OR, Aasen AJ. (2002d) Dammarane triterpenes from the resins of Commiphora confuse. Bull Chem Soc Ethiopia 16, 81-86.

135. Cardoso do Vale .J (1962) Chemical study of the barks of Commiphora angolensis. Bol Escola Farm, Univ Coimbra, Ed Cient 22, 113-128.

136. Schmeer K, Nicholson G, Zhang S, Bayer E, Bohning-Gaese K (1996) Identification of the lipids and the ant attractant 1,2-dioleoylglycerol in the arils of Commiphora guillaumini Perr. (Burseraceae) by supercritical fluid chromatography - atmospheric pressure chemical ionization mass spectrometry. J Chromatogr A $727,139-146$.

137. Manguro LO, Ugi I, Lemmen P. (2003) Dammarane Triterpenes of Commiphora confusa Resin. Chem Pharm Bull 51, 483-486. 